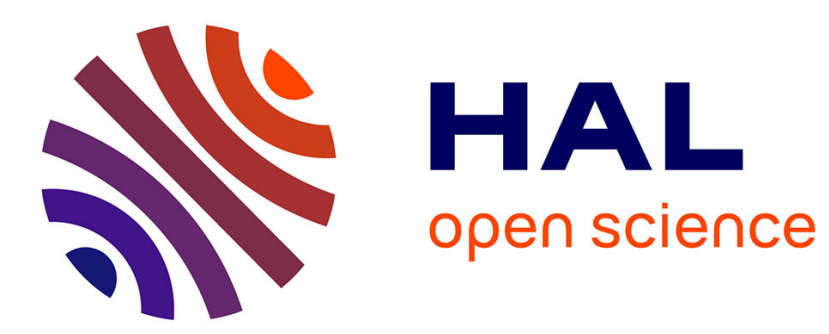

\title{
Pain matrices and neuropathic pain matrices: A review.
}

Luis Garcia Larrea, Roland Peyron

\section{To cite this version:}

Luis Garcia Larrea, Roland Peyron. Pain matrices and neuropathic pain matrices: A review.. Pain, 2013, 154 (Suppl 1), pp.S29-43. 10.1016/j.pain.2013.09.001 . inserm-00877368

\section{HAL Id: inserm-00877368 https://www.hal.inserm.fr/inserm-00877368}

Submitted on 28 Oct 2013

HAL is a multi-disciplinary open access archive for the deposit and dissemination of scientific research documents, whether they are published or not. The documents may come from teaching and research institutions in France or abroad, or from public or private research centers.
L'archive ouverte pluridisciplinaire HAL, est destinée au dépôt et à la diffusion de documents scientifiques de niveau recherche, publiés ou non, émanant des établissements d'enseignement et de recherche français ou étrangers, des laboratoires publics ou privés. 


\title{
Pain matrices and neuropathic pain matrices: a review
}

\author{
Luis Garcia-Larrea \& Roland Peyron
}

\begin{abstract}
The "pain matrix" is conceptualised here as a fluid system composed of several interacting networks. A 'nociceptive matrix' receiving spinothalamic projections (mainly posterior operculo-insular areas) ensures the bodily specificity of pain and is the only whose destruction entails selective pain deficits. Transition from cortical nociception to conscious pain relies on a second-order network including posterior parietal, prefrontal and anterior insular areas. $2^{\text {nd }}$-order regions are not nociceptive-specific: focal stimulation does not evoke pain and focal destruction does not produce analgesia, but their joint activation is necessary for conscious perception, attentional modulation and control of vegetative reactions. The ensuing pain experience can still be modified as a function of beliefs, emotions and expectations through activity of $3^{\text {rd }}$-order areas, including orbitofrontal and perigenual/limbic networks. The pain we remember results from continuous interaction of these subsystems, and substantial changes in the pain experience can be achieved by acting on each of them. Neuropathic pain (NP) is associated with changes in each of these levels of integration. The most robust abnormality in NP is a functional depression of thalamic activity, reversible with therapeutic manoeuvres and associated with rhythmic neural bursting. Neuropathic allodynia has been associated with enhancement of ipsilateral over contralateral insular activation, and lack of reactivity in orbitofrontal/perigenual areas. While lack of response of perigenual cortices may be an epiphenomenon of chronic pain, the enhancement of ipsilateral activity may reflect disinhibition of ipsilateral spinothalamic pathways due to depression of their contralateral counterpart. This in turn may bias perceptual networks and contribute to the subjective painful experience.
\end{abstract}

Key words: pain matrix; functional imaging; neuropathic pain; insula; thalamus; cingulate

\section{TRIALS AND TRIBULATIONS OF THE PAIN MATRIX}

"Concepts are tools: they wear out by ensuring their function" Claude Bernard

The concept of "pain matrix" defines a group of brain structures jointly activated by painful stimuli. It owes much to the notion of "neuromatrix" developed by Ronald Melzack, who proposed that the anatomical substratum of the physical self is a network of neurons extending throughout widespread areas of the brain (a "neuromatrix"), and generating characteristic patterns of neural impulses distinguishing each bodily sensation. In Melzack's words, "the neuromatrix for the physical self (..) generates the neurosignature pattern for pain" (Melzack 1990).

The Pain Matrix (PM) notion represented a conceptual advance over many prevailing concepts, which viewed pain-related emotional and cognitive phenomena as "reactions to", rather than components of pain (e.g. Hardy et al 1952). As early as 1968, Melzack and Casey suggested that 
the pain experience reflected interacting sensory, affective and cognitive dimensions which could influence each other. This view, of which the PM was an expansion, implied that there was no such thing as a "brain pain centre": pain was considered multidimensional and produced by distributed neural patterns, usually triggered by sensory inputs but potentially generated independently of them.

These theoretical notions were rapidly endorsed by functional imaging studies. Using positron-emission tomography (PET), two seminal papers in 1991 reported that noxious stimuli activated a distributed pattern of brain structures consistent with the notion of a 'pain matrix' (Jones et al 1991, Talbot et al 1991). A bulk of consistent data rapidly accumulated showing not only distributed activity to noxious inputs, but also linear and non-linear correlations between energy of the stimulus, subjective perception, and PM responses (e.g. Bornhovd et al 2002, Coghill et al 1999, Derbyshire et al 1997). It became also clear that most of the activated areas were not specific for pain: PM regions such as the anterior cingulate cortex (ACC), the anterior insula ( $\mathrm{Al})$, or the prefrontal and posterior parietal areas (PFC, PPC) showed enhanced activity in a wide range of nonpain experiments, especially in emotionally or cognitively-laden contexts, whereas the sensory encoding of noxious intensity was reflected by very tiny brain activations (Peyron et al 1999, Ploghaus et al 1999, Sawamoto et al 2000, 200z, reviews Peyron et al 2000a, Apkarian et al 2005).

Among the contrasting conceptual positions that have emerged since, some authors posit that functional imaging data may contain a genuine and objective "signature" of the painful experience (e.g. 2007, Wager et al 2013), which for a number of investigators may imply that functional imaging could be used to derive an 'individual pain phenotype' (see Borsook et al 2010, Cecchi et al 2012, Lu et al 2013, and comment in Apkarian 2013). Pushing this logic further, activation of PM subsets (essentially the anterior insulae and cingulate) has been sometimes equated with physical pain, leading to questionable conclusions such as that "social rejection hurts physically" (e.g. Eisenberger et al 2003, MacDonald \& Leary 2005). In contradistinction, other investigators have assailed the very concept of a specific pain-related network, claiming that most, if not all, the regions present in the PM represent a non-specific salience-detection system for the body, activated by relevant events "regardless of the sensory channel through which these events are conveyed" (lannetti et al 2008, lannetti and Mouraux 2010; review Legrain et al 2010). In between, the idea that the pain matrix cannot be unequivocally defined, the role of different regions being dependent on the context where stimuli are delivered, has been put forward by a few investigators (e.g. Peyron et al 2000, p.282; Tracey and Mantyh 2007, p. 379). 
Because spinothalamic projections inform brain networks on the bodily nature of the input, the healthy brain recognises at once whether a menacing signal arrives through a somatosensory channel. Information on the somatic origin is likely to be transferred to PM regions secondarily ignited, hence giving to perceptive networks a stable reference to the own body. In this review, the neural substrate of the pain experience will be conceptualised at different levels of progressively higher-order cortical networks, from cortical nociception to the conscious experience we call "pain" itself subject to reappraisal by internal states, feelings and beliefs prior to stabilisation into memory stores.

\section{First-order processing: a nociceptive cortical matrix}

The primate spinothalamic system (STS) chiefly originates from neurons in spinal laminæ I, V, and VII, whose axons terminate in multiple nuclei of the posterior thalamus, essentially the ventral posterior, centrolateral, mediodorsal and posterior group nuclei (Apkarian and Hodge 1989a,b; Mehler 1962, Rausell et al 1999). Using trans-synaptic viral transport, main spinothalamic cortical targets in primates were defined in the posterior insula ( 40\%), medial parietal operculum ( 30\%) and mid-cingulate cortex ( $24 \%$ ) (Dum et al 2009). These receiving regions are the source of the earliest responses to noxious stimuli recorded in the human brain (Frot et al 1999,2012; Lenz et al 1998c,d; Ohara et al 2006) and contain a 'nociceptive matrix' specific for spinothalamic projections. The posterior insula and inner operculum are the only regions in the human brain where stimulation triggers acute pain (Mazzola et al 2006, 2012), where focal lesions entail selective pain deficits (Biemond 1956, Greenspan et al 1999, Garcia-Larrea et al 2010), and where cortical injury gives rise to neuropathic pain (Biemond 1956, review Garcia-Larrea 2012). Lenz et al (1995) reported "full pain experiences" when stimulating thalamic regions projecting to the posterior insula and operculum, and intense pain was specifically reported during surgical dissection of the operculo-insular area, (Pereira et al 2005). Focal epileptic activity in the posterior insula can trigger painful seizures by igniting other PM areas in less than $100 \mathrm{~ms}$; in a recent report, painful seizures were stopped by millimetric thermo-coagulation of the posterior insular focus, and the patient has remained free from pain seizures for more than 2 years (Isnard et al 2011).

However, while this 'nociceptive matrix' appears as a necessary entry to generate physiological pain experiences, it cannot provide the countless nuances that characterise human pain, and is unable to sustain consciousness: indeed, activation of the nociceptive matrix persists during sleep, coma or vegetative state (Bastuji et al 2012, Boly et al 2008, Kassubek et al 2003). The transition from cortical nociception to conscious pain and its multiple attentional-cognitive modulations needs the recruitment of a second set of cortical networks. 


\section{From nociception to pain: a second-order perceptual matrix}

The 'classical' PM encompasses activity in many areas distinct from the nociceptive network described above, the most consistent being the mid- and anterior insulae, the anterior cingulate, prefrontal and posterior parietal areas, and with less consistency the striatum, supplementary motor area (SMA), hippocampus, cerebellum, and temporo-parietal junction. These second-order areas share a number of features: (i) none of them is a direct target of the spinothalamic system; (ii) direct stimulation does not evoke pain; (iii) selective destruction does not induce analgesia; (iv) they are also activated in contexts not involving pain, and $(v)$ their contribution to the PM, from nil to predominant, depends on the context where noxious stimuli are applied.

The mid- and anterior insulae participate almost constantly to the PM. Their activation may reflect a posterior-to-anterior information flux within the insula (Frot et al 2013, Pomares et al 2012), supporting the transformation of sensory events into vegetative reactions and associated internal feelings (Caruana et al 2011, Craig 2009, Wicker et al 2003). The "cognitive section" of the anterior cingulate (BA 24-32) is also consistently activated by painful stimuli (review Vogt 2005), and together with prefrontal and posterior parietal areas is thought to sustain attentional and evaluative processes of anticipation, learning and cognitive control. The contribution of these areas to the PM varies enormously with contextual factors (e.g. Buchel et al 2002, Peyron et al 1999, Seminowicz et al 2004; review Apkarian et al 2005), and their activation can be dissociated from actual stimulus intensity (e.g. Bornhovd et al 2002, Peyron et al 2007b). Activity in this $2^{\text {nd }}$-order contextual matrix can influence the nociceptive areas via top-down projections: attending actively to noxious stimuli enhances activity in sensory and orienting areas receiving STS afferents, such as the posterior insula and mid-cingulate, whereas distraction tends to suppress such activities (Bantick et al 2002, GarciaLarrea et al 1997, Lorenz et al 2005b, Ohara et al 2004, 2006; Valet et al 2004, review Wiech et al 2008). Such top-down influences modify perception by changing the sensory gain 'at the source', i.e. in cortical receiving areas (e.g. Garcia-Larrea et al 1991), thalamus (Vanhaudenhuyse et al 2009), and even at brainstem (Tracey et al 2002) and spinal cord (Sprenger et al 2012, Willer et al 1979). Further, vegetative peripheral reactions driven by anterior insular networks generate new ascending information through splachnic and vagus nerves, STT and dorsal column systems, thus providing new input to cortical and subcortical nociceptive targets (Tattersall et al 1986, Willis et al 1999). Of notice, hypnotic suggestions of hypo/hyperalgesia appear to influence either nociceptive, second-order or both matrices depending on the instructions given to the subject (eg Faymonville et al 2003, Hofbauer et al 2001, Rainville et al 1997,) consistent with its action through top-down influences. A dissociation between preserved activity in posterior insula but abated response in $2^{\text {nd }}$-order parietal and temporal cortices has also been described under hypnosis (Abrahamsen et al 2010). 
Regions of this $2^{\text {nd }}$ order matrix are activated in many contexts other than physical pain. For instance, the anterior insulae (AI) and anterior cingulate (ACC) pertain to a 'salience network' responding to behaviourally-relevant stimuli, which they integrate into perceptual decision-making (Wiech et al 2010). These two regions are jointly activated not only in response to painful stimuli, but also when subjects are confronted to unpleasant situations such as observing expressions of disgust (Wicker et al 2003), feeling guilt (Shin et al 2000), experiencing social and moral suffering (Eisenberger et al 2004, Kross et al 2011), or seeing / imagining other people in pain (Jackson et al 2005, Lamm et al 2010, Singer et al 2004). This has led to considerable controversy as to whether subjects confronted to such unpleasant situations do physically feel pain (e.g. Eisenberger et al 2004, Kross et al 2011). Obviously, this is not the case, at least in physiological conditions ${ }^{1}$ : neither the mid-anterior insula nor the rostral ACC pertain to the nociceptive matrix, and therefore cannot support by themselves the corporal specificity that characterises somatic pain, as shown in both stimulation and lesion studies (Greenspan et al 1999, Mazzola et al 2006, 2012). Their activation in response to unpleasant stimuli simply reflects their belonging to a broad system for salience detection which (a) generates internal state modifications and (b) alters the individual responsiveness to specific stimuli. In this vein, responses in both Al and ACC can be triggered by pleasant stimuli to the same degree as unpleasant ones (e.g. Harenski et al 2012, Herbert et al 2011, Wittmann et al 2010), and direct stimulation of the ventral (disgranular and agranular) insula in monkeys was able to elicit not only disgusting, but also socially affiliative behaviours (Caruana et al 2011).

Activity in the second-order pain matrix is also crucial to ensure the conscious perception of the stimulus, as sensory inputs become conscious only if they create distributed brain activation (Dehaene and Naccache 2001, Dehaene et al 2006). Activity constrained to unimodal areas does not produce conscious perception (e.g. Aru et al 2012, Del Cul 2007), which emerges only when sensory responses are associated to activation in parietal-temporal and prefrontal cortices, i.e. areas integrating the $2^{\text {nd }}$ order pain matrix. Functional connectivity within the frontoparietal network appears crucial for declarative consciousness (Långsjö et al 2012), and abundant evidence shows that the contribution of these regions separates undetected versus detected stimulus changes (Beck et al 2001, Pessoa et al 2004), masked versus unmasked words (Dehaene et al 2001, Haynes et al 2005), extinguished versus seen visual objects (Rees et al 2002), and missed versus reported stimuli during attentional blinks (Sergent et al 2005, Del Cul et al 2007). The functional coupling between stimulus-

\footnotetext{
${ }^{1}$ Transformation of visual or auditory sensations into somatic experiences has been described as rare conditions such as vision-touch synaesthesia (Blakemore et al 2005), which is seen as an "abnormal form of empathy" (Fitzgibbon et al 2010).
} 
specific areas and parieto-frontal networks is considered an essential signature of the access of sensory information to consciousness (Dehaene et al 2006, Del Cul et al 2007, Gross et al 2004, Haynes et al 2005, Liu et al 2011), making it available to high-level processes including perceptual categorization, long term memorization, evaluation, and intentional action.

To sum up, while the nociceptive matrix provides the sensory specificity of the pain experience, the joint activity of the nociceptive and second-order matrices is essential to ensure (a) the modulation of vegetative reactions and internal feelings via anterior insular networks; (b) the attentional modulation of sensory gain by top-down / bottom-up transaction, and (c) the access of nociceptive information to declarative consciousness.

\section{From immediate perception to pain memories: third-order networks}

Impressive changes of the pain experience can occur without changes in the matrices described above. For instance, the enhancement of subjective pain during the observation of other people's suffering (de Wied and Verbaten 2001, Godinho et al 2006, Loggia et al 2008) develops in the absence of significant changes in thalamus, insula, operculum or anterior cingulate, and is associated instead with activity in high-level polymodal regions outside the classical PM, such as the perigenual cingulate, the orbitofrontal cortex, the temporal pole and the anterolateral prefrontal areas (Godinho et al 2006, 2012). Similarly, the pain-relieving effects derived from placebo (Petrovic et al 2002, Wager et al 2004), self-control over the stimulus (Wiech et al 2006, Mohr et al 2012), or strong religious beliefs (Wiech et al 2008) are associated with activity changes in the orbitofrontal, perigenual cingulate and anterolateral prefrontal cortices, rather than in the nociceptive and the $2^{\text {nd }}$ order pain matrices. Orbitofrontal, perigenual and anterolateral prefrontal activities were also described when manipulating the context to transform an identical noxious stimulus from highly unpleasant to moderately pleasant (Leknes et al 2013). A full dissociation between 'core PM' activity and subjective pain reports was recently described during meditation-related analgesia, which was associated with enhanced activity in basic PM areas, but decreased activity in high-order prefrontal regions (Grant et al 2011).

Growing evidence supports a control hierarchy within the prefrontal cortex (PFC), whereby posterior-to-anterior development mediates progressively abstract control of perceptions and actions (Badre 2008), with ventromedial and perigenual areas involved in identification of the emotional significance of stimuli, production of affective states, and regulation of emotional responses (Kalisch et al 2006, Etkin et al 2011). In particular, the ventromedial PFC (orbitofrontal, perigenual) is considered as a region involved in the voluntary control of unpleasant emotions (Levesque et al 2003, Ohira et al 2006). While these areas are absent from the classically reported 
PM (Apkarian et al 2005), their activity appears able to sustain changes in subjective pain without involving sensory or low-level perceptive processes. At variance with pain modulations derived from selective attention or arousal, emotional manipulations do not appear to change pain experiences by increasing the sensory gain (which would be reflected in enhanced sensory responses), but rather by a "reappraisal" of immediate pain perceptions, in the sense of a reinterpretation of the meaning of a stimulus. Such high-level processes require working memory resources (Godinho et al 2006, Mohr et al 2011), involve medial and lateral prefrontal cortices (Kalisch et al 2006, Grant et al 2010, Godinho et al 2012), and appear to follow in time the activation of the basic PM, since the associated physiological changes only occur after the operculo-insular and cingulate activations have been elicited (Godinho et al 2006). Activity in such $3^{\text {rd }}$-order networks can therefore modify the immediate percepts driven by the nociceptive and second-order pain matrices.

Of importance, areas involved in the 'reappraisal' matrix such as the perigenual cingulate and orbitofrontal cortices are themselves strongly interconnected with subcortical regions crucial for descending pain control (notably the periaqueductal grey matter). Tonic activation of these areas may therefore not only support modifications in the subjective value of the nociceptive stimulus, but also contribute to a loop which changes the activity of ascending nociceptive systems, and by this bias influence the ascending input to cortical targets (see e.g. Leknes et al 2013). This point will be of importance when discussing PM changes during neuropathic pain below.

\section{The pain experience: an intersection of matrices}

The great merit of the PM concept was to underscore that pain experiences result from coordinated activity in a number of brain regions -i.e. the absence of any single "pain centre". While some investigators consider the PM as a genuine biomarker of the pain experience -a direct measure of the actual pain- others claim that the PM simply reflects a non-specific system of salience detection. The viewpoint proposed here, which elaborates and expands existing notions (e.g. Loeser 2000, Tracey \& Mantyh 2007) is that the final experience of pain (i.e. the pain we shall remember) results from the convolution of three orders of brain processing with progressive complexity, in networks that we may tentatively label as 'nociceptive', 'perceptive-attentional' and 'reappraisalemotional' matrices (Figure 1). Regions receiving spinothalamic input ensure the somatic-specific ('corporal') quality of the sensation; they trigger activity in parietal, frontal and anterior insular circuits supporting conscious perception, vegetative reactions and their modulation by attention and vigilance. The immediate perception issued from these activities can itself be modulated by higherorder networks driven by emotional contexts and internal states. This reappraisal determines a 
private generated assessment of instant percepts, tuning them up or down as a function of affective states and previous memories, and building what will represent the "subjective experience" available to long-term memory buffers. While dissociation of such different processing levels is useful for conceptualisation purposes, in real life their activity is interdependent and extremely fluid (see e.g. Craig 2009); hence the perception of pain appears as an active process, continuously re-constructing itself by integration of sensory inputs with ongoing memories and internal representations (Gregory 1997, Loeser 2000, Nakamura and Chapman 2002).

\section{IS THERE A “NEUROPATHIC PAIN MATRIX" ?}

"Constructing a model is making a bet" Anonymous

Previous literature has abundantly discussed brain activation differences between experimental and neuropathic pain (NP), but systematic investigations in large samples of NP patients remain an exception. Functional imaging in NP cannot be examined with the same confidence as the experimental studies reviewed above. Some features observed in NP are reproducible across studies, while others remain controversial; some particularities have been described in single case reports, but not reproduced in larger series. In some cases, similar results have been interpreted in different ways. While the set of brain structures activated during neuropathic hyperalgesia and allodynia grossly correspond to those of the "pain matrix", a number of features have been described that are highly characteristic of the neuropathic state. The most reproducible patterns associated with NP are: (i) tonic hypoactivity of the thalamus contralateral to the painful region; (ii) deficit in responsiveness of the ventromedial PFC (and often DL/ALPFC) during neuropathic allodynia, and (iii) change in the operculo-insular interhemispheric balance, with increased incidence of responses ipsilateral to pain.

\section{Thalamic hypoactivity in ongoing NP}

A deficit in thalamic metabolism contralateral to the side of NP was first described by Laterre et al (1988) in a patient with post-stroke syndrome. Shortly after, Di Piero and colleagues (1991) reported decrease in thalamic blood flow contralateral to the side of pain in 5 cancer patients with plexus invasion, the abnormality being reversible after successful cordotomy. Since then, the observation of functional thalamic depression contralateral to neuropathic pain (hypoperfusion / hypometabolism) has been replicated by at least 10 different teams using different pathological models and functional techniques, and is now one of the most robust and consistent observations in NP patients (Cahana et 
al 2004, De Salles and Bittar 1994, Di Piero et al 1991, Garcia-Larrea et al 2006, Hirato et al 1993, 1994; Hsieh et al 1995, ladarola et al 1995, Ito et al 2011, Kupers et al 2000, Pagni \& Canavero 1995, Peyron et al 1995, Tanaka et al 1997), although a few exceptions exist (Geha et al 2007, Hsieh et al 1999, Selvarajah et al 2011). The locus of functional depression within the thalamus (reported in about half of the cases) involved predominantly its posterior sections, consistent with the loci of arrival of ascending somatosensory afferents (Cahana et al 2004, Di Piero et al 1991, Hirato et al 1993, 1994; ladarola et al 1995, Hsieh et al 1995, Laterre et al 1988 ). While the robustness of thalamic hypoactivity in NP is widely acknowledged, its functional significance remains a matter of debate. Four questions incompletely solved are (a) its specificity regarding NP; (b) the role of sensory deafferentation; (c) the causal or consecutive nature of the dysfunction, and (d) the possible mechanisms leading to decreased local metabolism.

Specificity of thalamic hypoactivity. If not totally specific, thalamic hypoperfusion / hypometabolism is at least highly characteristic of ongoing neuropathic pain, and has not been described as a feature of mechanical, inflammatory or mixed pains which rather entail enhanced PM activity (e.g. May et al 2000, Wasan et al 2011). Although experimental tonic pain induced by capsaicin can mimic some NP features, it failed to reproduce the characteristic thalamic hypoactivity, and rather enhanced the thalamic perfusion (ladarola et al 1998, Witting et a 2001). Migraine with visual auras may have hypoperfusion in the occipital lobes (Kato et al 2010, Woods et al 1994; review Bartolini et al 2005), but in the rare cases where a migraine attack could be scanned on line, hypoperfusion either spared the thalamus (Woods et al 1994) or was bilateral despite unilateral attack (Kato et al 2010). Bilateral thalamic hypoactivity was described in early SPECT studies of 'central sensitisation' syndromes, such as chronic fatigue syndrome or fibromyalgia (Kwiatek et al 2000, Mountz et al 1998), but this has not been reproduced in more recent reports, which either did not find significant thalamic changes (e.g. Guedj et al 2007, Usui et al 2010, Wik et al 2003, Yunus et al 2004) or reported thalamic hyperperfusion (e.g. Diers et al 2011).

Thalamic hypoactivity and sensory deafferentation. Neuropathic pain occurs within areas of hypaesthesia, and therefore thalamic hypoactivity might be the result of sensory deafferentation. However, although deafferentation induces electrophysiological and metabolic changes in denervated thalami (Garraghty \& Kaas 1991, Lenz et al 1998, Nicolelis et al., 1993; Rasmusson 1996), it cannot fully explain the changes observed in NP patients. The fact that thalamic hypoperfusion was rapidly reversible with analgesic manoeuvres that left untouched, or increased, deafferentation, such as cordotomy (Di Piero 1991), motor cortex stimulation (Garcia-Larrea et al 1999, Peyron et al 1995) and propofol or lidocaine infusion (Cahana et al 2004, Canavero et al 1993, Hsieh et al 1995) 
indicates that the state of afferent information is not the decisive element maintaining thalamic hypoactivity. In one case with bilateral thalamic deafferentation, the thalamus contralateral to pain, albeit the less deafferented, showed the more severe hypoperfusion (Garcia-Larrea et al 2006). The contribution of deafferentation should not be neglected, however, as some thalamic asymmetry may persist even when differences in pain intensity are removed (Kupers et al 2000), and thalamic hypoactivity may be lacking in peripheral lesions inducing limited and indirect (functional) deafferentation (Geha et al 2007, Hsieh et al 1999, Selvarajah et al 2011). Current evidence suggests therefore that sensory deafferentation of the thalamus may represent an important primum movens triggering functional thalamic hypoactivity, which becomes eventually autonomous and participates to the pathophysiology of NP.

Is thalamic hypoactivity causal or consequential? Longer duration of pain is more likely associated with thalamic hypoperfusion (e.g. Fukumoto et al 1999) suggesting that either thalamic dysfunction is a consequence of pain or that patients who develop thalamic hypoactivity are more likely to develop long-lasting pain. In their seminal observations, Di Piero et al (1991) and ladarola et al (1995) considered the possibility that thalamic hypoactivity could reflect compensatory mechanisms of functional reorganisation after functional damage, hence being a consequence of the pain state. However, in patients submitted to analgesic procedures thalamic flow can increase significantly while pain still remains (Duncan et al 1998, Garcia-Larrea et al 1999, Peyron et al 1995) which is contradictory with the notion of its being an epiphenomenon of the pain itself. Also, thalamic flow increase during analgesia may be disproportionate and uncorrelated to pain relief (Kupers et al 2000), or may precede by hours/days clinical improvement (Fukui et al 2002, GarciaLarrea et al 1999, Tsubokawa et al 1993), suggesting that thalamic hypoactivity can hardly be interpreted as a compensatory epiphenomenon of the pain itself, and should be viewed as a functional concomitant of NP, reverted by analgesic procedures.

Which mechanisms underlie thalamic hypoactivity? Association of a "positive" symptom like pain with neural hypoactivity is a paradox. This paradox is not exclusive of NP and has been reported in other instances of positive symptoms such as epilepsy or movement disorders, where the affected regions show decreased flow / metabolism relative to the surrounding and contralateral tissue (Casse et al 2002, Theodore and Gaillard 2000, Weinand et al 1994, Hong et al 2002, Lai et al 2008, Saiki et al 2005). Spike neuronal bursting and EEG slowing are found in hypometabolic epileptogenic regions (Abou-Khalil et al 1987, Merlet et al 1996), as well as in the thalamus of patients with neuropathic pain (Gücer et al., 1978; Hirato et al 1994, Hirayama et al 1989, Lenz et al 1987, 1994, 1998a; Modesti and Waszak 1975, Rinaldi et al 1991, Sarnthein \& Jeanmonod 2008, Yamashiro et al 1994), 
and in animals models of deafferentation (Albe-Fessard et al 1985, Lombard et al 1979, Tsubokawa et al 1991a, Weng et al 2000, 2003). Rather than reflect "neuronal hyperactivity" (Koyama et al 1993, Rinaldi et al 1991, Tsubokawa et al 1991a), it was soon acknowledged that thalamic bursts in neuropathic pain fulfilled the criteria of "low-threshold calcium spikes" (LTS) (Jeanmonod et al 1993, 1996; Lenz et al 1989, Weng et al 2003) reflecting a state of thalamic cell inhibition by hyperpolarisation (Lenz et al 1989, Llinas and Jahnsen, 1982, Steriade et al 1993). Combined PET-scan and intrathalamic recordings in central post-stroke pain demonstrated a direct link between hypometabolism and thalamic bursting (Hirato et al 1993,1994), and hence thalamic LTS bursting is a good candidate to provide the neurophysiological basis for NP thalamic hypoactivity in functional imaging. Although thalamic deactivation can be dissociated from deafferentation (see above), deafferentation may be its primum movens, and probably a condition necessary but not sufficient for rhythmic bursting to occur. Models of neural network deafferentation in epilepsy suggest that the arrival of sparse inputs during refractory periods and the sprouting of remaining afferents may favour the development of abnormal spikes (Engel 1989). The possible relevance of these epilepsy models regarding rhythmic bursting in the thalamus of NP patients remains however highly uncertain.

The relationship between thalamic bursting and NP pathophysiology remains a point of strong controversy. A number of authors suggested that abnormal thalamic bursts were intimately related to the genesis of central pain (Hirato et al 1994, Jeanmonod et al 1993, Lenz et al 1987), and enhanced thalamo-cortical coherence for low-frequency EEG rhythms was interpreted as LTS-related resonant thalamo-cortical interactions (Canavero 1994, Jeanmonod et al 1993, Llinas et al 1999, Magnin et al 2005, Sarnthein et al 2003). The occasional observations that small lesions interrupting the thalamo-cortical connections may terminate instantly central post-stroke pain (Soria \& Fine 1991, Yarnitsky et al 1988) were in line with this hypothesis. In sharp contradistinction, investigators that had participated in the original discovery of thalamic LTS bursts reported them to be equally prevalent in pain and non-pain patients, suggesting that their presence was not necessarily related to the occurrence of NP (Radhakrishnan et al 1999). In parkisonian patients LTS prevail in motor rather than somatosensory thalamic regions (Magnin et al 2000), while the reverse is true in pain patients with phantom limb pain (Lenz et al., 1998b), suggesting that the spatial distribution of bursting within the thalamus might be, by virtue of different cortical projections, the crucial element determining whether the associated clinical expression will be or not pain-related. In this vein, microstimulation in areas of increased bursting within the ventrocaudal thalamus is more likely to produce pain than in other areas of VPL (Davis et al 1998, Lenz et al 1998b).

In summary, the functional thalamic depression in NP appears to reflect mechanisms that, once triggered by anatomical deafferentation, favour the transition to neuropathic pain. Resting 
thalamic hypoactivity may represent the metabolic counterpart of abnormal thalamic bursting observed in these patients. However, before considering this phenomenon as a putative marker of neuropathic pain, direct comparison of thalamic activity in series of patients with similar lesions, but presenting or not with NP, appears mandatory. Longitudinal studies are also needed to determine whether or not patients with thalamic functional findings at NP onset are more likely to develop uncontrolled NP. Should this be the case, assessment of thalamic blood flow might become a means to estimate the likelihood of developing NP after a potentially pain-inducing neural lesion.

\section{Provoked pain: allodynia and hyperalgesia $(\mathrm{A} / \mathrm{H})$}

Provoked pain permits easier access to haemodynamic imaging than ongoing pain, and therefore studies of stimulus-evoked NP largely outnumber those assessing its continuous component. Provoked neuropathic pain can be contrasted with surrogate models of allodynia or hyperalgesia which generate experimentally controlled abnormal pain sensations. These models, mostly based on capsaicin injections, share with NP the induction of anomalous peripheral and central sensitisation, but lack the somatosensory deafferentation which is a key feature of NP.

\section{Experimental hyperalgesia and allodynia. (Table 1)}

When compared with either a resting state or non-painful stimuli, experimental allodynia is consistently associated with activation in the posterior operculo-insular region, the anterior insulae, the mid- and anterior cingulate, and the posterior parietal and prefrontal cortices (Table 1). Responses in "3 ${ }^{\text {rd }}$-order" regions linked to emotional appraisal are more variable: activation of perigenual and orbitofrontal cortices was reported in a majority of experimental studies (i.e. ladarola 1998, Kupers et al 2004, Lee et al 2008, Lorenz et al 2002, 03, 05a, Maihofner \& Handwerker 2005a, Moulton et al 2007 (brush), Wiech et al 2005, Witting et al 2001, Zambreanu et al 2005) but was absent in others (Baron et al 1999, Maihofner et al 2004, lannetti et al 2005, Shenoy et al 2011). Activation of these areas may reflect methodological issues such as the acquisition methods (PET vs. fMRI) or the presence/absence of ongoing pain, but also appears contingent to the degree of unpleasantness attained during the experiment: Lorenz and co-workers (2002, 2005a) used capsaicin to compare 'physiological' pain with allodynic pain of matched intensity but much higher unpleasantness scores. The latter yielded significant blood flow enhancement in perigenual, orbitofrontal and ventral striatal regions not activated by 'normal' thermal pain (see figure 5 in Lorenz et al 2002). These authors underscored that midfrontal activity moved from the caudal cingulate (BA24) during normal pain toward perigenual cingulate areas during heat allodynia (Lorenz 2002). Maihofner and Handwerker (2005a) also showed that activity in the medial PFC correlated with enhanced unpleasantness in thermal versus mechanical allodynia, and other authors have 
speculated that mid-frontal and perigenual activation in pain studies may be associated to higher pain ratings (see eg Kupers et al 2004, p.290). The specific activations in ventromedial PFC during highly-unpleasant allodynia have been considered to reflect recruitment of associative-limbic loops (Lorenz et al 2002, 2005a), possibly enhanced by anticipation phenomena (e.g. Ploghaus et al 1999).

Enhanced perigenual / orbitofrontal activity associated with intense offensiveness of the stimulus can also, and simultaneously, set up powerful mechanisms aimed at controlling pain. Indeed, ventromedial frontal areas have been considered crucial for the control of unpleasantness (Levesque et al 2003, Ohira et al 2006), and during experimental allodynia their activity is most often accompanied by midbrain activation in regions consistent with the periaqueductal grey matter (PAG) (ladarola et al 1998, Kupers et al 2004, Lee et al 2008, Lorenz et al 2002, 2005a; Zambreanu et al 2005), while such brainstem contribution was absent in cases with no ventromedial activation (Maihofner et al 2004, Shenoy et al 2011, Witting et al 2001). The PAG is one of the major sites involved in descending, opioid-mediated inhibition of pain (Basbaum \& Fields 1984, Boivie and Meyerson 1982, Derbyshire \& Osborn 2009, Reynolds 1969). Functional connectivity between the orbitofrontal cortex, the perigenual cingulate and the PAG has been demonstrated in man (e.g. Peyron et al 2007a, Valet et al 2004) and activity enhancement in both regions is typically associated to successful analgesia by opioid administration (Firestone et al 1996), distraction (Valet et al 2004), neurostimulation (Peyron et al 2007, Willoch et al 2003) and placebo (Petrovic et al 2002). Thus, the exquisite enhancement of midfrontal, perigenual and upper brainstem regions during experimental allodynia may not only reflect an internal state of high unpleasantness, but also the triggering of descending controls aimed at interrupting, or at least down-regulating, an abnormally enhanced nociceptive inflow (review in Garcia-Larrea \& Peyron 2007). The negative correlation observed between brainstem activity and pain scores during hyperalgesia due to opioid withdrawal also supports a pain-inhibitory role of upper brainstem activation (Wanigakesera et al 2011). Notwithstanding the above, brainstem activity has also been occasionally considered as an index of descending facilitatory processes (e.g. lannetti et al 2005, Lee et al 2008, Zambreanu et al 2005), thereby reflecting mechanisms that maintain central sensitisation rather than controlling it (Ossipov et al 2000).

\section{Neuropathic hyperalgesia / allodynia (Table 2)}

Grouped analysis of neuropathic $\mathrm{A} / \mathrm{H}$ is hindered with drawbacks that have been well summarised by Kupers and Kehlet (2006). These include the heterogeneity in pain location (different zones stimulated across patients introduce confounding effects), the use of the homologous contralateral body as control, which may itself be subject to abnormal sensitivity (Casey et al 2012), as well as the study of patients who differ in their cause, duration, and level of spontaneous pain. We 
tried to circumvent some of these difficulties by stressing the consistency of findings across studies, rather than the quantitative importance of the findings. Since the crucial variable was consistency, we may have underestimated important changes that only a few studies were able to tag. Although there is large overlap between networks activated during experimental and neuropathic allodynia (e.g. Lanz et al 2011), the latter is associated to characteristic quantitative and qualitative changes. Quantitatively, the blood flow response is out of proportion with the actual intensity of the stimulus: the response magnitude to subtle rubbing of the skin may become virtually identical to that observed to 'normal' painful stimuli (Peyron et al 2013). In addition, responses during neuropathic allodynia exhibit qualitative changes, in particular (a) the transformation of thalamic resting hypoactivity into hyperactivity, with possible changes in activated nuclei; (b) the displacement of operculo-insular equilibrium toward the hemisphere ipsilateral to pain, and (c) the lack of reactiveness of ventromedial PFC.

Transformation of thalamic hypoactivity into hyperactivity. Cesaro et al (1991) first drove attention to the association of hyperpathia and thalamic hyperactivity in 2 patients with central NP (see Fig 4 in Cesaro 91). At the group level, thalamic hyperactivity to mechano-thermal allodynia was demonstrated by Peyron et al (1998) in 9 patients with Wallenberg syndrome, and has been confirmed since in a number of studies (e.g. Casey 1999, 2000, Geha et al 2008, Kupers et al 2011). It has been speculated that NP hypoactivity in the thalamus at rest may mask an underlying hyperresponsiveness to external stimulation due to loss of resting intra-thalamic inhibition (Casey et al 2000, 2012; Cesaro et al 1986). Thalamic hypoactivity in ongoing NP has been associated with abnormal thalamic bursting (see above), which, in the context of epilepsy, has been suggested to paradoxically favour the development of hyper-reactivity to external inputs (Engel 1989). More recent data indicates that thalamic hyper-responsiveness in central pain patients may concern medial, rather than lateral thalamic subregions (Casey et al 2012, Peyron et al 2013).

Changes in inter-hemispheric activation balance. Haemodynamic activation of the contralateral operculo-insular (OI) cortex in experimental pain is more frequently reported than that of its ipsilateral counterpart, while this is reversed in neuropathic allodynia where ipsilateral OI activation predominates. As a result, the ipisilateral/contralateral incidence ratio passes from $50 \%$ (experimental) to $111 \%$ (neuropathic allodynia) in the operculum, and from $80 \%$ (experimental) to $160 \%$ (neuropathic) in the insula $(p<0.001$; Figure 2 ). Such paradoxical lateralisation towards the hemisphere ipsilateral to allodynia has been described in patients with cortical damage (Peyron et al $2000 \mathrm{~b}, 2004)$, but also in the absence of direct cortical lesions, as in peripheral neuropathy or spinal injury (Ducreux et al 2006, Petrovic et al 1999, Witting et al 2006) (Figure 3). In other cases both 
posterior insulae were activated, but only the ipsilateral side remained significant after contrasting allodynic versus non-painful control stimuli (e.g. Schweinhardt et al 2006). In accordance with these data, the ALE meta-analysis of Lanz et al (2011) showed the insula activated bilaterally in experimental hyperalgesia, but rather ipsilaterally in NP patients (Table 3 in Lanz et al 2011).

Disinhibition of ipsilateral thermo-algesic pathways appears as a likely candidate to support the enhancement of ipsilateral activity in NP, and this ipsilateral overreaction may be mechanistically related to painful symptoms. It has been estimated that about $17 \%$ of primate spinothalamic axons project to the ipsilateral thalamus (Apkarian and Hodge 1989a,b, Chung et al 1986), and clinical data indicates that ipsilateral transmission, normally suppressed when both spinothalamic pathways are intact, may become functional after a unilateral lesion (Bowsher 1988, Nagaro et al 1993, Nathan 1956). Based on detailed psychophysical testing, Casey et al (2012) suggested bilateral effects of unilateral spinothalamic lesions, and uncrossed painful symptoms have been described in patients with neuropathic pain from unilateral lesions (Kim 1998, Canavero et al 1999). Central pain ipsilateral to a brain lesion may mirror the site of previous contralateral pain (Kim 1998), and post-stroke allodynia can be abolished by a new lesion involving $\mathrm{Ol}$ areas in the other hemisphere (Daniele et al 2003, Helmchen et al 2002). In physiological conditions, Ol activity contralateral to the stimulus is thought to inhibit tonically its ipsilateral counterpart (Bowsher 1988, Nagaro et al 1993, Kim 1998), such inhibition being overcome only at intensely noxious levels (e.g. ladarola et al 98, Maihofner et al 2004, Witting et al 2001). Therefore, significant ipsilateral OI responses may be physiologically encoded as a signal specifically associated to very strong nociceptive input. Disinhibition of ipsilateral responses following a neuropathic lesion might also be (erroneously) interpreted by perceptive networks as a signal that the magnitude of the stimulus was abnormally high. Under this perspective, overactivation of the ipsilateral OI region would directly contribute to a perceptive bias sustaining the subjectively enhanced sensation.

Deficit in ventro-medial prefrontal activation. A second source of imbalance in neuropathic allodynia concerns the activity in ventromedial PFC. While activation enhancement in sensory regions has been similarly reported in experimental or neuropathic allodynia (Figure 2), a conspicuous feature of neuropathic allodynia is the lack of activation of ventromedial (perigenual and orbitofrontal) PFC. Grouped analysis of 39 published reports shows that the incidence of ventromedial frontal activation was significantly lower in neuropathic than in experimental allodynia ( $17 \%$ vs $58 \%, p<0.01$ ), while the mid and caudal cingulate sections (MCC - ACC, BA 24-32) were equally activated in both instances (67\% vs $71 \%$, ns) (Figure 2). The response shortfall of ventromedial PFC in neuropathic allodynia has been reproduced by many independent groups and different pain models, including central post-stroke pain (Peyron et al 1998, 2000, 2004), 
syringomyelia (Ducreux et al 2006), peripheral neuropathy (Maihofner et al 2003, Petrovic et al 1999, Schweinhardt et al 2006), trigeminal or postherpetic neuralgia (Becerra et al 2006, Geha et al 2008) and CRPS (Maihofner et al 2005b). Dampened perigenual responses were also incidentally reported during ongoing NP (Hsieh et al 1995). Some reports underscored the large variability of perigenual activation, which could be present in individual patients yet absent in group analysis, and suggested that high pre-activation levels due to background pain might prevent further increases in neuropathic allodynia (Witting et al 2006). Such 'ceiling effect' appears however unlikely since, in healthy subjects, significant ongoing pain due to capsaicin injection did not prevent ventromedial activation during allodynia (Kupers et al 2004, Maihofner \& Handwerker 2005a, Witting et al 2001). Further, ventromedial frontal activity in NP could even decrease during allodynic pain (e.g. Kupers et al 2011, Peyron et al 1998) or be anticorrelated with pain intensity (Geha et al 2008).

As part of a corticolimbic circuitry, the perigenual and orbitofrontal cortices have important roles in the integration of cognitive and emotionally relevant information (Etkin et al 2011, Kalisch et al 2006). They are crucial to cope adaptively with physiological challenges (Fuchs and Flugge 2003) and to support production and regulation of affective states (Levesque et al 2003, Phillips et al 2003). This region is also the source of descending connections which, in animal models, trigger opioid-mediated inhibition of pain signals via the periaqueductal grey (Al Maskati et al 1989, Basbaum \& Fields 1984, Reynolds 1969). In accordance with this, enhanced functional connectivity between perigenual and PAG regions correlates with pain relief (Peyron et al 2007, Valet et al 2004), and all kind of analgesic procedures in humans triggers perigenual and orbitofrontal activity, hence compensating their functional depression (e.g. Davis et al 2000, Hsieh et al 1995, Valet et al 2004, Willoch et al 2003; review in Garcia-Larrea \& Peyron 2007) (Figure 4). In the same vein, decreased ventromedial activation in somatoform pain disorder has been interpreted as a diminished top-down inhibition of ascending pain pathways (Gündel et al 2008).

Chronic stressors entail morphological changes in ventromedial PFC: prolonged immobilization simplifies the branching and shorten the apical dendrites of rat ACC neurons -a damage reversible following a stress-free period (Radley and Morrison 2005). Such structural changes lead to functional depression and may result from release of glucocorticoids and excitatory amino-acids via PFC glutamate neurotransmission (review Moghaddam 2002). As a chronic stressor, NP can also trigger the above cascades, and lead to reduced responsiveness of ventromedial PFC as a consequence rather than a cause of chronic NP. This is consistent with the fact that similar ventromedial depression has been reported in patients with non-neuropathic pain (Albuquerque et al 2006, Jones and Derbyshire 1995, 1997). In turn, weakening of ventromedial PFC function may decrease descending pain-inhibitory signals, with relative unleash of ascending noxious input and therefore still increased pain. As a maladaptive consequence of persistent pain, lack of ventromedial 
responsiveness would not only change the subjective appraisal of the pain experience, but also limit the system's capacities to react adaptively to ascending pain signals.

\section{Other features of neuropathic allodynia}

Tables and Figure 2 also show a drastic decrease in the reporting of lateral prefrontal cortex activation in neuropathic $\mathrm{A} / \mathrm{H}$, as compared with experimental studies ( $50 \%$ vs $90 \%$ ). Lateral PFC can exert active control on pain perception through top-down influences on sensory cortices and, via the thalamus and the cingulate, on midbrain structures (Lorenz et al., 2003; Valet et al., 2004). Data from experimental models in rodents have not yielded univocal results: while ventromedial PFC stimulation is quite consistently antinociceptive (Al Maskati \& Zbrozyna 1989, Hardy \& Holmes 1996), that of lateral PFC has been occasionally found to enhance nociceptive responses (shorten the latency of tail flick and enhance activity of rostroventral "on" cells; Huchinson et al 1996). Given the enormous volume of prefrontal cortex in humans, it is likely that multiple interacting networks with different contributions to pain processing are simultaneously active during experimental and neuropathic allodynia, precluding any firm discussion at this point.

\section{Conclusions}

Data reviewed in this paper allow drawing some tentative mechanistic conclusions on the relation between brain activity and normal and abnormal pain sensations. Concerning neuropathic pain, studies with larger sample sizes are badly needed, as well as adequate control of a number of crucial variables including fluctuations of spontaneous pain, magnitude of sensory deafferentation, changes in brain morphology, and baseline blood flow or BOLD signals at rest. Yet, although largely incomplete, existing data also show that functional imaging is now able to go beyond the phenomenological description of a 'physiological photograph', and propose testable hypotheses that will, or will not, come true in the following years. Above all, data from dozens of laboratories in the world underscore that pain, normal or abnormal, is an emergent property of the brain, lending substance to the nociception-perception-suffering model (Loeser 2000). As stated by Loeser (2000): "it is suffering, not pain, that brings patients into doctor's offices. Suffering is an emergent property of the human brain and is dependent upon consciousness". Only the study of integrated brain function will eventually lead to its correct understanding and proper management. 


\section{Acknowledgements}

"This work was supported by the Louise and Allan Edwards Foundation (Ronald Melzack Award 2012), the French Society for the evaluation and therapy of Pain (Translational Research Grant 2012), and the LABEX CORTEX (ANR-11-LABX-0042) of Universite de Lyon, within the program "Investissements d'Avenir" (ANR-11-IDEX-0007) operated by the French National Research Agency (ANR)."

\section{The authors declare no conflict of interest}

\section{References}

1. Abou-Khalil BW, Siegel GJ, Sackellares JC, Gilman S, Hichwa R, Marshall R. Positron emission tomography studies of cerebral glucose metabolism in chronic partial epilepsy. Ann Neurol. 1987;22:480-6.

2. Abrahamsen R, Dietz M, Lodahl S, Roepstorff A, Zachariae R, Ostergaard L, Svensson P. Effect of hypnotic pain modulation on brain activity in patients with temporomandibular disorder pain. Pain 2010;151: 825-33.

3. Albe-Fessard D, Berkley KJ, Kruger L, Ralston HJ 3rd, Willis WD Jr. Diencephalic mechanisms of pain sensation. Brain Res. 1985;356:217-96.

4. Al Maskati HA, Zbrozyna AW. Stimulation in prefrontal cortex area inhibits cardiovascular and motor components of the defence reaction in rats. J Auton Nerv Syst. 1989;28:117-25.

5. Apkarian AV. A neural signature for pain. Trends in Cognitive Sciences 2013; 17:309-10.

6. Apkarian AV, Hodge CJ. Primate spinothalamic pathways: II. The cells of origin of the dorsolateral and ventral spinothalamic pathways. J Comp Neurol. 1989a;288:474-92.

7. Apkarian AV, Hodge CJ. Primate spinothalamic pathways: III. Thalamic terminations of the dorsolateral and ventral spinothalamic pathways. J Comp Neurol 1989b;288:493-511.

8. Apkarian AV, Bushnell MC, Treede RD, Zubieta JK. Human brain mechanisms of pain perception and regulation in health and disease. Eur J Pain. 2005;9:463-84.

9. Aru J, Axmacher N, Do Lam ATA, Fell J, Elger CE, Singer W, Melloni L. Local Category-Specific Gamma Band Responses in the Visual Cortex Do Not Reflect Conscious Perception. J Neurosci 2102, 32:14909 14.

10. Badre D. Cognitive control, hierarchy, and the rostro-caudal organization of the frontal lobes. Trends Cogn Sci. 2008 May;12(5):193-200.

11. Baliki MN, Petre B, Torbey S, Herrmann KM, Huang L, Schnitzer TJ, Fields HL, Apkarian AV. Corticostriatal functional connectivity predicts transition to chronic back pain. Nat Neurosci. 2012;15:1117-9.

12. Bantick SJ, Wise RG, Ploghaus A, Clare S, Smith SM, Tracey I. Imaging how attention modulates pain in humans using functional MRI. Brain 2002;125:310-9. 
13. Bartolini M, Baruffaldi R, Paolino I, Silvestrini M. Cerebral blood flow changes in the different phases of migraine. Funct Neurol. 2005;20:209-11.

14. Baron R, Baron Y, Disbrow E, Roberts TP. Brain processing of capsaicin-induced secondary hyperalgesia: a functional MRI study. Neurology 1999;53:548-57

15. Basbaum Al, Fields HL. Endogenous pain control systems: brainstem spinal pathways and endorphin circuitry. Annual Review of Neuroscience 1984; 7:309-338.

16. Bastuji H, Mazza S, Perchet $C$, Frot M, Mauguière F, Magnin M, Garcia-Larrea L. Filtering the reality: functional dissociation of lateral and medial pain systems during sleep in humans. Hum Brain Mapp. 2012;33:2638-49.

17. Beck DM, Rees G, Frith CD, Lavie N. Neural correlates of change detection and change blindness. Nat Neurosci. 2001;4:645-50.

18. Biemond A. The conduction of pain above the level of the thalamus opticus. Archives of Neurology Psychiatry 1956; 75 : 231-244.

19. Becerra L, Morris S, Bazes S, Gostic R, Sherman S, Gostic J, Pendse G, Moulton E, Scrivani S, Keith D, Chizh B, Borsook D. Trigeminal neuropathic pain alters responses in CNS circuits to mechanical (brush) and thermal (cold and heat) stimuli. J Neurosci. 2006;26 :10646-57.

20. Blakemore SJ, Bristow D, Bird G, Frith C, Ward J. Somatosensory activations during the observation of touch and a case of vision-touch synaesthesia. Brain 2005;128:1571-83.

21. Boivie J. Central Post-Stroke Pain. In Handbook of Clinical Neurology, 2006, Vol 81 (3rd series), F Cervero \& T Jenssen, Eds, Elsevier, Ch. 48, pp.715-730.

22. Boivie J, Leijon G, Johansson I. Central post-stroke pain--a study of the mechanisms through analyses of the sensory abnormalities. Pain 1989;37:173-185.

23. Boivie J, Meyerson BA. A correlative anatomical and clinical study of pain suppression by deep brain stimulation. Pain 1982; 13:113-126.

24. Boly M, Faymonville ME, Schnakers C, Peigneux P, Lambermont B, Phillips C, Lancellotti P, Luxen A, Lamy $M$, Moonen $G$, Maquet $P$, Laureys $S$. Perception of pain in the minimally conscious state with PET activation: an observational study. Lancet Neurol. 2008; 7:1013-20.

25. Bornhovd K, Quante M, Glauche V, Bromm B, Weiller C, Buchel C. Painful stimuli evoke different stimulus-response functions in the mygdale, prefrontal, insula and somatosensory cortex: a single-trial fMRI study. Brain 2002;125:1326-36.

26. Borsook D, Sava S, Becerra L. The pain imaging revolution: advancing pain into the $21^{\text {st }}$ century. Neuroscientist 2010; 16: 171-185.

27. Bowsher D. Contralateral mirror-image pain following anterolateral cordotomy. Pain 1988;33:63-5.

28. Bowsher D. Central pain: clinical and physiological characteristics, J Neurol Neurosurg Psychiatr 1995; 61:62-69.

29. Bowsher D, Somatic sensation and the insular-opercular cortex: relationship to central pain, Eur Neurol 2006;55: 160-165.

30. Brooks JCW, Bimson WE, Roberts N, Nurmikko TJ. Functional magnetic resonance imaging of capsaicininduced thermal hyperalgesia. In: Dostrovsky JO, Carr DB, Koltzenburg M, editors. Proceedings of the $10^{\text {th }}$ World Congress on Pain. Seattle: IASP Press; 2003:295-304. 
31. Buchel C, Bornhovd K, Quante M, Glauche V, Bromm B, Weiller C. Dissociable neural responses related to pain intensity, stimulus intensity, and stimulus awareness within the anterior cingulate cortex: a parametric single-trial laser functional magnetic resonance imaging study. J Neurosci 2002;22:970976.

32. Cahana A, Carota A, Montadon ML, Annoni JM. The long-term effect of repeated intravenous lidocaine on central pain and possible correlation in positron emission tomography measurements. Anesth Analg. 2004;98:1581-4.

33. Canavero S, Pagni CA, Castellano G, Bonicalzi V, Bello M, Duca S, Podio V. The Role of Cortex in Central Pain Syndromes: Preliminary Results of a Long-Term Technetium-99 Hexamethylpropyleneamineoxime Single Photon Emission Computed Tomography Study. Neurosurgery 1993 ; 32: 185-191.

34. Canavero S. Dynamic reverberation. A unified mechanism for central and phantom pain. Med Hypotheses 1994;42: 203-7.

35. Canavero S, Bonicalzi V. Bilateral central pain with unilateral brain lesion. European Neurology 1999; 42: 2:118.

36. Casey KL. Abstracts: 9th World Congress on Pain. Seattle: IASP Press, 1999, pp 435-436. (Cited in Casey KL: Imaging pain, Pain Clinical Updates 2000; IASP Press Vol VIII (4):1-8.

37. Casey KL. Concepts of pain mechanisms: the contribution of functional imaging of the human brain. In: Sandkühler J, Bromm B, Gebhart GF, editors. Nervous system plasticity and chronic pain, Progress in brain research, 129. Amsterdam: Elsevier, 2000. pp. 277-288.

38. Casey KL, Geisser M, Lorenz J, Morrow TJ, Paulson P, Minoshima S. Psychophysical and cerebral responses to heat stimulation in patients with central pain, painless central sensory loss, and in healthy persons. Pain 2012;153:331-41.

39. Casse R, Rowe CC, Newton M, Berlangieri SU, Scott AM. Positron emission tomography and epilepsy. Mol Imaging Biol. 2002;4:338-51.

40. Cecchi GA, Huang L, Hashmi JA, Baliki M, Centeno MV, Rish I, Apkarian AV. Predictive dynamics of human pain perception. PLoS Comput Biol. 2012;8:e1002719.

41. Cesaro P, Amsallem B, Pollin B, Nguyen-Legros J, Moretti JL. Organization of the median and intralaminar nuclei of the thalamus: hypotheses on their role in the onset of certain central pain. Rev Neurol 1986;142: 297-302.

42. Cesaro P, Mann MW, Moretti JL, Defer G, Roualdés B, Nguyen JP, Degos JD. Central pain and thalamic hyperactivity: a single photon emission computerized tomographic study. Pain 1991;47:329-36.

43. Coghill RC, Sang CN, Maisog JM, ladarola MJ. Pain intensity processing within the human brain: a bilateral, distributed mechanism. J Neurophysiol 1999;82: 1934-1943.

44. Craig AD. How do you feel--now? The anterior insula and human awareness. Nat Rev Neurosci. 2009;10:59-70.

45. Chung JM, Lee KH, Surmeier DJ, Sorkin LS, Kim J, Willis WD. Response characteristics of neurons in the ventral posterior lateral nucleus of the monkey thalamus. J Neurophysiol 1986;56:370-90.

46. Daniele O, Fierro B, Brighina F, Magaudda A, Natalè E. Disappearance of haemorrhagic stroke-induced thalamic (central) pain following a further (contralateral ischaemic) stroke. Funct Neurol. 2003;18:956. 
47. Dasheiff RM. A review of interictal cerebral blood flow in the evaluation of patients for epilepsy surgery. Seizure. 1992;1: 117-25.

48. Davis KD, Kiss ZH, Luo L, Tasker RR, Lozano AM, Dostrovsky JO. Phantom sensations generated by thalamic microstimulation. Nature. 1998;391:385-7.

49. Davis KD, Taub E, Duffner F, Lozano AM, Tasker RR, Houle S, Dostrovsky JO. Activation of the anterior cingulate cortex by thalamic stimulation in patients with chronic pain: a positron emission tomography study. J Neurosurgery 2000; 92, 64-69.

50. Dehaene S, Naccache L. Towards a cognitive neuroscience of consciousness: basic evidence and a workspace framework. Cognition 2001;79:1-37.

51. Dehaene S, Naccache L, Cohen L, Bihan DL, Mangin JF, Poline JB, Rivière D. Cerebral mechanisms of word masking and unconscious repetition priming. Nat. Neurosci. 2001; 4: 752-758.

52. Dehaene S, Changeux JP, Naccache L, Sackur J, Sergent C. Conscious, preconscious, and subliminal processing: a testable taxonomy. Trends Cogn Sci. 2006;10:204-11.

53. Del Cul A, Baillet S, Dehaene S. Brain dynamics underlying the nonlinear threshold for access to consciousness. PLoS Biol. 2007 Oct;5(10):e260.

54. Derbyshire SWG, Jones AKP, Gyulai F, Clark S, Townsend D, Firestone LL. Pain processing during three levels of noxious stimulation produces differential patterns of central activity. Pain 1997;73:431-445.

55. Derbyshire SW, Osborn J. Offset analgesia is mediated by activation in the region of the periaqueductal grey and rostral ventromedial medulla. Neuroimage 2009;47:1002-06.

56. De Salles AA, Bittar GT Jr. Thalamic pain syndrome: anatomic and metabolic correlation. Surg Neurol. 1994; 41:147-51.

57. de Wied M, Verbaten MN. Affective pictures processing, attention, and pain tolerance. Pain. 2001;90:163-72.

58. Diers M, Schley MT, Rance M, Yilmaz P, Lauer L, Rukwied R, Schmelz M, Flor H. Differential central pain processing following repetitive intramuscular proton/prostaglandin E2 injections in female fibromyalgia patients and healthy controls. Eur J Pain. 2011;15:716-23.

59. Di Piero V, Jones AKP, lannotti F, Powell M, Perani D, Lenzi GL, Frakowiak RSJ. Chronic pain: a PET study of the central effects of percutaneous high cervical cordotomy. Pain 1991; 46: 9-12.

60. Ducreux D, Attal N, Parker F, Bouhassira D. Mechanisms of central neuropathic pain: a combined psychophysical and fMRI study in syringomyelia. Brain. 2006;129:963-76.

61. Dum RP, Levinthal DJ, Strick PL. The spinothalamic system targets motor and sensory areas in the cerebral cortex of monkeys. J Neurosci 2009;29:14223-35.

62. Duncan GH, Kupers RC, Marchand S, Villemure JG, Gybels JM, Bushnell MC. Stimulation of human thalamus for pain relief: possible modulatory circuits revealed by positron emission tomography. J Neurophysiol. 1998;80:3326-30.

63. Eisenberger NI, Lieberman MD, Williams KD. Does Rejection Hurt? An fMRI Study of Social Exclusion. Science 2003; 302 :290-292.

64. Eisenberger NI, Lieberman MD. Why rejection hurts: a common neural alarm system for physical and social pain. Trends Cogn Sci. 2004;8:294-300. 
65. Engel Jr J. New concepts on the epileptic focus. In: Wieser HG, Speckmann EJ, Engel J, editors. The epileptic focus. Basel: Karger; 1989. p. 83-93 [chapter 6].

66. Etkin A, Egner T, Kalisch R. Emotional processing in anterior cingulate and medial prefrontal cortex. Trends Cogn Sci. 2011;15:85-93.

67. Firestone LL, Gyulai F, Mintun M, Adler L, Urso K, Winter PM. Human brain activity response to fentanyl imaged by positron emission tomography. Anesth Analg. 1996;82:1247-51.

68. Fitzgibbon BM, Giummarra MJ, Georgiou-Karistianis N, Enticott PG, Bradshaw JL. Shared pain: from empathy to synaesthesia. Neurosci Biobehav Rev 2010;34:500-12.

69. Frot M, Rambaud L, Guenot M, Mauguiere F. Intracortical recordings of early pain-related CO2-laser evoked potentials in the human second somatosensory (SII) area. Clin Neurophysiol. 1999;110:133-45.

70. Frot $M$, Magnin M, Mauguière F, Garcia-Larrea L. Cortical representation of pain in primary sensorymotor areas (S1/M1)-a study using intracortical recordings in humans. Hum Brain Mapp. 2012 Jun 15. doi: $10.1002 / \mathrm{hbm} .22097$.

71. Frot M, Faillenot I, Mauguière F. Spatio-temporal gradient of pain evoked responses in the human insula. (2013, submitted)

72. Fuchs E, Flügge G. Chronic social stress: effects on limbic brain structures. Physiol Behav. 2003;79:41727.

73. Fukui S, Shigemori S, Nosaka S. Changes in regional cerebral blood flow in the thalamus after electroconvulsive therapy for patients with complex regional pain syndrome type 1 (preliminary case series). Reg Anesth Pain Med 2002;27:529-32.

74. Fukumoto M, Ushida T, Zinchuk VS, Yamamoto Y, Yoshida S. Contralateral thalamic perfusion in patients with reflex sympathetic dystrophy syndrome. Lancet 1999; 354: 1790-91.

75. Garcia-Larrea L, Bastuji H, Mauguière F. Mapping study of somatosensory evoked potentials during selective spatial attention. Electroencephalogr Clin Neurophysiol. 1991;80:201-14.

76. Garcia-Larrea L, Peyron R, Laurent B, Mauguiere F. Association and dissociation between laser-evoked potentials and pain perception. Neuroreport. 1997;8:3785-9.

77. Garcia-Larrea L, Peyron R, Mertens P, Gregoire MC, Lavenne F, Le Bars D, Convers P, Mauguiere F, Sindou M, Laurent B. Electrical stimulation of motor cortex for pain control: a combined PET-scan and electrophysiological study. Pain 1999;83:259-73.

78. Garcia-Larrea L, Maarrawi J, Peyron R, Costes N, Mertens P, Magnin M, Laurent B. On the relation between sensory deafferentation, pain and thalamic activity in Wallenberg's syndrome: A PET-scan study before and after motor cortex stimulation. Eur J Pain 2006, 10: 677-88.

79. Garcia-Larrea L, Peyron R. Motor cortex stimulation for neuropathic pain: From phenomenology to mechanisms. Neuroimage, 2007, 37 (S1): 71-9.

80. Garcia-Larrea L, Perchet C, Creac'h C, Convers P, Peyron R, Laurent B, Mauguière F, Magnin M. Operculo-insular pain (parasylvian pain): a distinct central pain syndrome. Brain 2010;133: 2528-39.

81. Garcia-Larrea L. The posterior insular-opercular region and the search of a primary cortex for pain. Neurophysiol Clin. 2012; 42:299-313. 
82. Geha PY, Baliki MN, Chialvo DR, Harden RN, Paice JA, Apkarian AV. Brain activity for spontaneous pain of postherpetic neuralgia and its modulation by lidocaine patch therapy. Pain. 2007;128:88-100.

83. Geha PY, Baliki MN, Wang X, Harden RN, Paice JA, Apkarian AV. Brain dynamics for perception of tactile allodynia (touch-induced pain) in postherpetic neuralgia. Pain. 2008;138:641-56.

84. Godinho F, Magnin M, Frot M, Perchet C, Garcia-Larrea L. Emotional modulation of pain: is it the sensation or what we recall? J Neurosci. 2006; 26: 11454-61.

85. Godinho F, Faillenot I, Perchet C, Magnin M, Garcia-Larrea L. How the pain of others enhances our pain: Searching the cerebral correlates of "compassional hyperalgesia". Eur J Pain 2012; 16:748-59.

86. Grant JA, Courtemanche J, Rainville P. A non-elaborative mental stance and decoupling of executive and pain-related cortices predicts low pain sensitivity in Zen meditators. Pain 2011;152:150-6.

87. Greenspan JD, Lee RR, Lenz FA. Pain sensitivity alterations as a function of lesion location in the parasylvian cortex. Pain. 1999;81:273-82.

88. Gregory RL. Knowledge in perception and illusion. Philos Trans R Soc Lond B Biol Sci. 1997; 352:112127.

89. Gücer G, Niedermeyer E, Long M. Thalamic EEG recordings in patients with chronic pain. J Neurol 1978, 219: 47-61.

90. Guedj E, Taieb D, Cammilleri S, Lussato D, de Laforte C, Niboyet J, Mundler O. 99mTc-ECD brain perfusion SPECT in hyperalgesic fibromyalgia. Eur J Nucl Med Mol Imaging. 2007; 34:130-4.

91. Gündel H, Valet M, Sorg C, Huber D, Zimmer C, Sprenger T, Tölle TR. Altered cerebral response to noxious heat stimulation in patients with somatoform pain disorder. Pain 2008;137:413-21.

92. Hardy JD, Wolff HG, Goodell H. Pain Sensations and reactions. Williams \& Wilkins, Oxford, England (1952). 435 pp.

93. Harenski CL, Thornton DM, Harenski KA, Decety J, Kiehl KA. Increased frontotemporal activation during pain observation in sexual sadism: preliminary findings. Arch Gen Psychiatry. 2012 Mar;69(3):283-92.

94. Haynes JD, Driver J, Rees G. Visibility reflects dynamic changes of effective connectivity between V1 and fusiform cortex. Neuron 2005;46:811-21.

95. Helmchen C, Lindig M, Petersen D, Tronnier V. Disappearance of central thalamic pain syndrome after contralateral parietal lobe lesion: implications for therapeutic brain stimulation. Pain 2002;98:325-30.

96. Herbert C, Herbert BM, Pauli P. Emotional self-reference: brain structures involved in the processing of words describing one's own emotions. Neuropsychologia 2011;49:2947-56.

97. Hirato M, Horikoshi S, Kawashima Y, Satake K, Shibasaki T, Ohye C. The possible role of the cerebral cortex adjacent to the central sulcus for the genesis of central (thalamic) pain--a metabolic study. Acta Neurochir Suppl (Wien). 1993;58:141-4.

98. Hirato M, Watanabe K, Takahashi A, Hayase N, Horikoshi S, Shibasaki T, Ohye C. Pathophysiology of central (thalamic) pain: combined change of sensory thalamus with cerebral cortex around central sulcus. Stereotact Funct Neurosurg. 1994;62:300-3.

99. Hirayama T, Dostrovsky JO, Gorecki J, Tasker RR, Lenz FA. Recordings of abnormal activity in patients with deafferentation and central pain. Stereotact Funct Neurosurg. 1989;52:120-6. 
100. Hofbauer RK, Rainville P, Duncan GH, Bushnell MC. Cortical representation of the sensory dimension of pain. J Neurophysiol $2001 \mathrm{Jul} ; 86(1): 402-11$

101. Hsieh JC, M Belfrage, S Stoneelander, P Hansson, M Ingvar. Central representation of chronic ongoing neuropathic pain studied with positron emission tomography. Pain 1995, 63: 225-236.

102. Hsieh JC, Meyerson BA, Ingvar M. PET study on central processing of pain in trigeminal neuropathy. Eur J Pain 1999;3:51-65.

103. Hong YH, Ahn TB, Oh CW, Jeon BS. Hemichorea as an initial manifestation of moyamoya disease: reversible striatal hypoperfusion demonstrated on single photon emission computed tomography. Mov Disord. 2002;17:1380-83.

104. Iadarola MJ, Max MB, Berman KF, Byassmith MG, Coghill RC, Gracely RH, Bennett GJ. Unilateral decrease in thalamic activity observed with positron emission tomography in patients with chronic neuropathic pain. Pain 1995; 63: 55-64.

105. Iadarola MJ, Berman KF, Zeffiro TA, Byassmith MG, Gracely RH, Max MB, Bennett GJ. Neural activation during acute capsaicin-evoked pain and allodynia assessed with PET. Brain 1997;121:931-947.

106. Iannetti GD, Zambreanu L, Wise RG, Buchanan TJ, Huggins JP, Smart TS, Vennart W, Tracey I. Pharmacological modulation of pain-related brain activity during normal and central sensitization states in humans. Proc Natl Acad Sci U S A. 2005;102:18195-200.

107. lannetti GD, Hughes NP, Lee MC, Mouraux A. Determinants of laser-evoked EEG responses: pain perception or stimulus saliency? J Neurophysiol. 2008;100:815-28.

108. Iannetti GD, Mouraux A. From the neuromatrix to the pain matrix (and back). Exp Brain Res. 2010; 205:1-12.

109. Isnard J, Magnin M, Jung J, Mauguière F, Garcia-Larrea L. Does the insula tell our brain that we are in pain? Pain 2011;152:946-51.

110. Ito M, Kuroda S, Shiga T, Tamaki N, Iwasaki Y. Motor cortex stimulation improves local cerebral glucose metabolism in the ipsilateral thalamus in patients with poststroke pain: case report. Neurosurgery 2011;69:E462-9.

111. Jackson PL, Meltzoff AN, Decety J. How do we perceive the pain of others? A window into the neural processes involved in empathy. Neuroimage 2005, 24:771-9.

112. Jeanmonod D, Magnin M, Morel A. Thalamus and neurogenic pain: physiological, anatomical and clinical data. Neuroreport 1993, 4: 475-478.

113. Jeanmonod D, Magnin M, Morel A. Low-threshold calcium spike bursts in the human thalamus Common physiopathology for sensory, motor and limbic positive symptoms. Brain 1996 ; 119 : 363375 .

114. Jones AKP, Brown WD, Friston KJ, Qi LY and Frakowiak RSJ. Cortical and subcortical localization of response to pain in man using positron emission tomography. Proc. Roy. Soc. Lond (series B) 1991: 244: 39-44.

115. Jones AKP, Derbyshire SWG. PET imaging of pain-related somatosensory cortical activity. Pain and the Brain (Series: Advances in Pain Research and Therapy 22 (1995), pp 213-227

116. Jones AKP, Derbyshire SWG. Reduced cortical responses to noxious heat in patients with rheumatoid arthritis.Annals of the Rheumatic Diseases 1997; 56: 601-607. 
117. Kalisch R, Wiech K, Critchley HD, Dolan RJ. Levels of appraisal: a medial prefrontal role in high-level appraisal of emotional material. Neuroimage. 2006;30:1458-66.

118. Kassubek J, Juengling FD, Els T, Spreer J, Herpers M, Krause T, Moser E, Lücking CH. Activation of a residual cortical network during painful stimulation in long-term postanoxic vegetative state: a 150H2O PET study. J Neurol Sci. 2003;212:85-91.

119. Kato Y, Araki N, Matsuda H, Ito Y, Suzuki C. Arterial spin-labeled MRI study of migraine attacks treated with rizatriptan. J Headache Pain 2010;11:255-8.

120. Kim JS. Delayed-onset ipsilateral sensory symptoms in patients with central poststroke pain. Eur Neurol 1998;40:201-6.

121. Kim JS. Aggravation of poststroke sensory symptoms after a second stroke on the opposite side. Eur Neurol 1999;42:200-4.

122. Kim JS. Patterns of sensory abnormality in cortical stroke: evidence for a dichotomized sensory system. Neurology 2007;68:174-80.

123. Koyama S, Katayama Y, Majima S, Hirayama T, Fujii M, Tsubokawa T. Thalamic neuronal hyperactivity following transection of the spinothalamic tract in the cat: involvement of NMDA receptor. Brain Research 1993, 612: 343-350.

124. Kross E, Berman MG, Mischel W, Smith EE, Wager TD. Social rejection shares somatosensory representations with physical pain. Proc Natl Acad Sci U S A. 2011;108:6270-5.

125. Kupers RC, Gybels JM, Gjedde A. Positron emission tomography study of a chronic pain patient successfully treated with somatosensory thalamic stimulation. Pain 2000;87:295-302.

126. Kupers RC, Svensson P, Jensen TS. Central representation of muscle pain and mechanical hyperesthesia in the orofacial region: a positron emission tomography study. Pain 2004;108: 284-93.

127. Kupers R, Kehlet H. Brain imaging of clinical pain states: a critical review and strategies for future studies. Lancet Neurol. 2006; 5:1033-44.

128. Kupers R, Lonsdale MN, Aasvang E, Kehlet H. A positron emission tomography study of wind-up pain in chronic postherniotomy pain. Eur J Pain. 2011;15:698.e1-16.

129. Kwiatek R, Barnden L, Tedman R, et al. Regional cerebral blood flow in fibromyalgia: singlephotonemission computed tomography evidence of reduction in the pontine tegmentum and thalami. Arthritis Rheum 2000; 43: 2823-2833.

130. Lai MH, Wang TY, Chang CC, Tsai KC, Chang ST. Hemichorea associated with gabapentin therapy with hypoperfusion in contralateral basal ganglion - a case of a paraplegic patient with neuropathic pain. J Clin Pharm Ther. 2008;33:83-6.

131. Lamm C, Decety J, Singer T. Meta-analytic evidence for common and distinct neural networks associated with directly experienced pain and empathy for pain. Neuroimage. 2011;54:2492-502.

132. Långsjö JW, Alkire MT, Kaskinoro K, Hayama H, Maksimow A, Kaisti KK, Aalto S, Aantaa R, Jääskeläinen $\mathrm{SK}$, Revonsuo A, Scheinin H. Returning from oblivion: imaging the neural core of consciousness. J Neurosci. 2012;32:4935-43.

133. Lanz S, Seifert F, Maihöfner C. Brain activity associated with pain, hyperalgesia and allodynia: an ALE meta-analysis. J Neural Transm 2011;118:1139-54. 
134. Laterre EC, De Volder AG, Goffinet AM. Brain glucose metabolism in thalamic syndrome. J Neurol Neurosurg Psychiatry 1988;51(3):427-8.

135. Legrain V, lannetti GD, Plaghki L, Mouraux A. The pain matrix reloaded A salience detection system for the body. Prog Neurobiol. 2010; 93:111-24.

136. Leknes S, Berna C, Lee MC, Snyder GD, Biele G, Tracey I. The importance of context: when relative relief renders pain pleasant. Pain 2013;154:402-10.

137. Lenz FA, Tasker RR, Dostrovsky JO, Kwan HC, Gorecki J, Hirayama T, et al. Abnormal single-unit activity recorded in the somatosensory thalamus of a quadriplegic patient with central pain. Pain 1987;31:225-36.

138. Lenz FA, Kwan HC, Dostrovsky JO, Tasker RR. Characteristics of the bursting pattern of action potentials that occurs in the thalamus of patients with central pain. Brain Res 1989;496:357-60.

139. Lenz FA, Kwan HC, Martin R, Tasker R, Richardson RT, Dostrovsky JO. Characteristics of somatotopic organization and spontaneous neural activity in the region of the thalamic principal sensory nucleus in patients with spinal cord transection. J Neurophysiol 1994;72:1570-87.

140. Lenz FA, Gracely RH, Romanoski AJ, Hope EJ, Rowaland LH, Dougherty PM. Stimulation in the human somatosensory thalamus can reproduce both the affective and sensory dimensions of previously experienced pain. Nature Medicine 1995; 1: 910-913

141. Lenz FA, Garonzik IM, Zirh TA, Dougherty PM. Neuronal activity in the region of the thalamic principal sensory nucleus (ventralis caudalis) in patients with pain following amputations. Neuroscience 1998a; $86: 1065-81$.

142. Lenz F. A., Gracely R. H., Baker F. H., Richardson R. T. and Dougherty P. M. Reorganization of sensory modalities evoked by microstimulation in region of the thalamic principal sensory nucleus in patients with pain due to nervous system injury. J. comp. Neurol. 1998b; 399: 125-138.

143. Lenz FA, Rios M, Zirh A, Chau D, Krauss G, Lesser RP. Painful stimuli evoke potentials recorded over the human anterior cingulate gyrus. J Neurophysiol 1998c;79:2231-4.

144. Lenz FA, Rios M, Chau D, Krauss GL, Zirh TA, Lesser RP. Painful stimuli evoke potentials recorded from the parasylvian cortex in humans. J Neurophysiol 1998d;80:2077-88.

145. Lee MC, Zambreanu L, Menon DK, Tracey I. Identifying brain activity specifically related to the maintenance and perceptual consequence of central sensitization in humans. J Neurosci 2008;28:11642-49.

146. Levesque J, Eugene F, Joanette Y, Paquette V, Mensour B, Beaudoin G et al. Neural circuitry underlying voluntary suppression of sadness. Biol. Psychiatry 2003; 53: 502-10.

147. Llinas R, Jahnsen H. Electrophysiology of mammalian thalamic neurones in vitro. Nature 1982;297:4068.

148. Llinas RR, Ribary U, Jeanmonod D, Kronberg E, Mitra PP. Thalamocortical dysrhythmia: A neurological and neuropsychiatric syndrome characterized by magnetoencephalography. Proc Natl Acad Sci U S A. 1999; 96:15222-27

149. Loeser JD: Pain and suffering. Clin J Pain 2000; 16:S2-S6.

150. Loggia ML, Mogil JS, Bushnell MC. Empathy hurts: compassion for another increases both sensory and affective components of pain perception. Pain 2008;136:168-76. 
151. Lombard MC, Nashold BS Jr, Albe-Fessard D, Salman N, Sakr C. Deafferentation hypersensitivity in the rat after dorsal rhizotomy: a possible animal model of chronic pain. Pain 1979;6:163-74.

152. Lorenz J, Cross D, Minoshima S, Morrow T, Paulson P, Casey K. A unique representation of heat allodynia in the human brain. Neuron 2002;35:383-93

153. Lorenz J, Minoshima S, Casey KL. Keeping pain out of mind: the role of the dorsolateral prefrontal cortex in pain modulation. Brain 2003;126:1079-91.

154. Lorenz J, Casey KL. Imaging of acute versus pathological pain in humans. Eur J Pain 2005a;9 : 163-5.

155. Lorenz J, Hauck M, Paur RC, Nakamura Y, Zimmermann R, Bromm B, Engel AK. Cortical correlates of false expectations during pain intensity judgments--a possible manifestation of placebo/nocebo cognitions. Brain Behav Immun. 2005b;19:283-95.

156. Lu Y, Klein GT, Wang MY. Can pain be measured objectively? Neurosurgery. 2013;73:N24-5.

157. Macdonald G, Leary MR. Why does social exclusion hurt? The relationship between social and physical pain. Psychol Bull. 2005;131:202-23.

158. Magnin M, Morel A, Jeanmonod D. Single-unit analysis of the pallidum, thalamus and subthalamic nucleus in parkinsonian patients. Neuroscience. 2000;96:549-64.

159. Magnin M, Morel A, Jeanmonod D. Toward a unified theory of positive symptoms. Neurophysiol Clin. 2005;35:154-61.

160. Maihofner C, Neundorfer B, Stefan H, Handwerker HO. Cortical processing of brush-evoked allodynia. Neuroreport 2003;14:785-9.

161. Maihofner C, Schmelz M, Forster C, Neundorfer B, Handwerker HO. Neural activation during experimental allodynia: a functional magnetic resonance imaging study. Eur J Neurosci. 2004;19:32118.

162. Maihofner C, Handwerker HO. Differential coding of hyperalgesia in the human brain: a functional MRI study. Neuroimage 2005a;28:996-1006.

163. Maihofner C, Forster C, Birklein F, Neundörfer B, Handwerker HO. Brain processing during mechanical hyperalgesia in complex regional pain syndrome: a functional MRI study. Pain 2005b;114:93-103.

164. May A, Bahra A, Büchel C, Frackowiak RS, Goadsby PJ. PET and MRA findings in cluster headache and MRA in experimental pain. Neurology 2000; 55:1328-35.

165. Mazzola L, Isnard J, Mauguiere F. Somatosensory and pain responses to stimulation of the second somatosensory area (SII) in humans. A comparison with SI and insular responses. Cereb Cortex 2006;16:960-8.

166. Mazzola L, Isnard J, Peyron R, Mauguière F. Stimulation of the human cortex and the experience of pain: Wilder Penfield's observations revisited. Brain 2012;135:631-40.

167. Mehler WR. The anatomy of the so-called "pain tract" in man. An analysis of the course and distribution of the ascending figers of the fasciculus anterolateralis. In: Basic research in paraplegia, Ed by John D French and Robert W Porter, Charles C Thomas Publisher, Springfield, III, USA, 1962, pp. 2655 .

168. Melzack R, Casey KL. Sensory, motivational, and central control determinants of pain. In: The Skin Senses (DR Kenshalo, ed, 1968) Springfield, III : pp.423-435. 
169. Melzack R. Phantom limb and the concept of a neuromatrix. TINS 1990; 13:88-92.

170. Merlet I, Garcia-Larrea L, Grégoire MC, Lavenne F, Mauguière F. Source propagation of interictal spikes in temporal lobe epilepsy. Correlations between spike dipole modelling and [18F]fluorodeoxyglucose PET data. Brain 1996;119:377-92.

171. Modesti LM, Waszak M. Firing pattern of cells in human thalamus during dorsal column stimulation. Appl Neurophysiol. 1975;38:251-8.

172. Mohr C, Leyendecker S, Petersen D, Helmchen C. Effects of perceived and exerted pain control on neural activity during pain relief in experimental heat hyperalgesia: a fMRI study. Eur J Pain 2012;16:496-508.

173. Moulton EA, Pendse G, Morris S, Strassman A, Aiello-Lammens M, Becerra L, Borsook D. Capsaicininduced thermal hyperalgesia and sensitization in the human trigeminal nociceptive pathway: an $\mathrm{fMRI}$ study. Neuroimage 2007;35:1586-600.

174. Mountz JM, Bradley LA, Alarcon GS: Abnormal functional activity of the central nervous system in fibromyalgia syndrome. Am J Med Sci 1998, 315:385-396.

175. Nagaro T, Amakawa K, Kimura S, Arai T. Reference of pain following percutaneous cervical cordotomy. Pain 1993;53:205-11.

176. Nakamura Y, Chapman CR. Measuring pain: an introspective look at introspection. Conscious Cogn. 2002;11:582-92.

177. Nathan PW. Reference of sensation at the spinal level. J Neurol Neurosurg Psychiatry 1956;19:88-100.

178. Ohara S, Crone NE, Weiss N, Lenz FA. Attention to a painful cutaneous laser stimulus modulates electrocorticographic event-related desynchronization in humans. Clin Neurophysiol. 2004;115:164152.

179. Ohara S, Anderson WS, Lawson HC, Lee HT, Lenz FA. Endogenous and exogenous modulators of potentials evoked by a painful cutaneous laser (LEPs). Acta Neurochir Suppl. 2006;99:77-9.

180. Ohira H, Nomura, M, Ichikawa N, Isowa, T, lidaka T, Sato, A, et al.. Association of neural and physiological responses during voluntary emotion suppression. Neurolmage 2006; 29: 721-33

181. Ossipov MH, Hong Sun T, Malan PJr, Lai J, Porreca F. Mediation of spinal nerve injury induced tactile allodynia by descending facilitatory pathways in the dorsolateral funiculus in rats. Neurosci Lett 2000; 290:129-32.

182. Pagni CA, Canavero S. Functional thalamic depression in a case of reversible central pain due to a spinal intramedullary cyst - Case report. Journal of Neurosurgery 1995; 83: 163-16.

183. Petrovic $\mathrm{P}$, Ingvar $\mathrm{M}$, Stone-Elander S, Petersson KM, Hansson P. A PET activation study of dynamic mechanical allodynia in patients with mononeuropathy. Pain 1999;83:459-70.

184. Petrovic P, Kalso E, Magnus Petersson K, Ingvar M. Placebo and Opioid Analgesia. Imaging a Shared Neuronal Network. Science 2002; 295:1737-40

185. Pereira LC, Modesto AM, Sugai R, da Mota LA. Pain sensitive cerebral areas and intracranial structures revealed at fully awake craniotomies for primary intracranial tumor ressection. Communication to the 11th World Congress of the IASP (2005). Pain Program No. 1517-P20. Sydney, Australia.

186. Pessoa L, Ungerleider LG. Neural correlates of change detection and change blindness in a working memory task. Cereb Cortex 2004;14:511-20. 
187. Peyron R, Garcia-Larrea L, Deiber MP, Cinotti L, Convers P, Sindou M, Mauguiere F, Laurent B. Electrical stimulation of precentral cortical area in the treatment of central pain: electrophysiological and PET study. Pain 1995; 62:275-286.

188. Peyron R, L Garcia-Larrea, MC Gregoire, P Convers, F Lavenne, L Veyre, JC Froment, F Mauguiere, D Michel, B Laurent. Allodynia after lateral-medullary (Wallenberg) infarct - A PET study. Brain 1998; 121: 345-356

189. Peyron R, Garcia-Larrea L, Gregoire MC, Costes N, Convers P, Lavenne F, Mauguiere F, Michel D, Laurent $\mathrm{B}$. Haemodynamic brain responses to acute pain in humans: sensory and attentional networks. Brain 1999;122:1765-80.

190. Peyron R, Laurent B, Garcia-Larrea L. Functional imaging of brain responses to pain. A review and meta-analysis. Neurophysiol Clin 2000a;30:263-88.

191. Peyron R, Garcia-Larrea, Gregoire MC, Convers P, Lavenne F, Bonnefoi F, Mauguière F, Manet L, Barral FG, Michel D, Laurent B. Parietal and cingulate processing in central pain. A Positron Emission Tomography study. Pain 2000b; 84: 77-87.

192. Peyron R, Schneider F, Faillenot I, Convers P, Barral FG, Garcia-Larrea L,Laurent B. An fMRI study of cortical representation of mechanical allodynia in patients with neuropathic pain. Neurology. 2004;63:1838-46.

193. Peyron R, Faillenot I, Mertens P, Laurent B, Garcia-Larrea L. Motor cortex stimulation in neuropathic pain. Correlations between analgesic effect and hemodynamic changes in the brain. A PET study. Neuroimage 2007a;34:310-21.

194. Peyron R, Kupers R, Jehl JL, Garcia-Larrea L, Convers P, Barral FG, Laurent B. Central representation of the RIII flexion reflex associated with overt motor reaction: an fMRI study. Neurophysiol Clin. 2007b;37:249-59.

195. Peyron R, Faillenot I, Pomares FB, Le Bars D, Garcia-Larrea L, Laurent B. Mechanical allodynia in neuropathic pain. Where are the brain representations located? A positron emission tomography (PET) study. Eur J Pain. 2013 Mar 27. doi: 10.1002/j.1532-2149.2013.00307.x.

196. Phillips ML, Drevets WC, Rauch SL, Lane R. Neurobiology of emotion perception I: The neural basis of normal emotion perception. Biol Psychiatry 2003;54:504-14.

197. Ploghaus A, Tracey I, Gati J.S, Clare S, Menon RS, MatthewsPM, Rawlins JNP. Dissociating pain from its anticipation in the human brain. Science 1999; 284:1979-1981.

198. Pomares FB, Faillenot I, Barral FG, Peyron R. The 'where' and the 'when' of the BOLD response to pain in the insular cortex. Discussion on amplitudes and latencies. Neuroimage. 2013;64:466-75.

199. Radhakrishnan V, Tsoukatos J, Davis KD, Tasker RR, Lozano AM, Dostrovsky JO. A comparison of the burst activity of lateral thalamic neurons in chronic pain and non-pain patients. Pain 1999; 80:567-75.

200. Radley JJ, Morrison JH. Repeated stress and structural plasticity in the brain. Ageing Res Rev. 2005;4:271-87.

201. Rainville P, Duncan GH, Price DD, Carrier B, Bushnell MC. Pain affect encoded in human anterior cingulate but not somatosensory cortex. Science $1997 ; 15 ; 277: 968-71$

202. Rees G, Wojciulik E, Clarke K, Husain M, Frith C, Driver J. Neural correlates of conscious and unconscious vision in parietal extinction. Neurocase 2002; 8, 387-393. 
203. Reynolds DV. Surgery in the rat during electrical analgesia induced by focal brain stimulation. Science 1969; 164:444-445.

204. Rinaldi PC, Young RF, Albe-Fessard D, Chodakiewitz J. Spontaneous neuronal hyperactivity in the medial and intralaminar thalamic nuclei of patients with deafferentation pain. J Neurosurg 1991, 74: 415-421.

205. Saiki M, Saiki S, Gondo Y, Murata KY, Sakai K, Hirose G. Ictal alteration of 99mTc ECD SPECT imaging in a patient with secondary paroxysmal kinesigenic dyskinesia caused by hyperglycemia. Rinsho Shinkeigaku 2005;45:312-6.

206. Sarnthein J, Morel A, von Stein A, Jeanmonod D. Thalamic theta field potentials and EEG: high thalamocortical coherence in patients with neurogenic pain, epilepsy and movement disorders. Thalamus \& Related Systems 2003, 2: 231-238

207. Sarnthein J, Jeanmonod D. High thalamocortical theta coherence in patients with neurogenic pain. Neuroimage 2008;39:1910-7.

208. Sawamoto N, Honda M, Okada T, Hanakawa T, Kanda M, Fukuyama H, Konishi J, Shibasaki H. Expectation of pain enhances responses to nonpainful somatosensory stimulation in the anterior cingulate cortex and parietal operculum/posterior insula: an event-related functional magnetic resonance imaging study. J Neurosci 2000;20:7438-45.

209. Schweinhardt P, Glynn C, Brooks J, McQuay H, Jack T, Chessell I, Bountra C, Tracey I. An fMRI study of cerebral processing of brush-evoked allodynia in neuropathic pain patients. Neuroimage 2006;32:25665 .

210. Selvarajah D, Wilkinson ID, Gandhi R, Griffiths PD, Tesfaye S. Microvascular perfusion abnormalities of the Thalamus in painful but not painless diabetic polyneuropathy: a clue to the pathogenesis of pain in type 1 diabetes. Diabetes Care 2011;34:718-20.

211. Seminowicz DA, Mikulis DJ, Davis KD. Cognitive modulation of pain-related brain responses depends on behavioral strategy. Pain 2004;112:48-58.

212. Sergent $C$, Baillet $S$, Dehaene $S$. Timing of the brain events underlying access to consciousness during the attentional blink. Nat Neurosci 2005; 8: 1391-400.

213. Shenoy R, Roberts K, Papadaki A, McRobbie D, Timmers M, Meert T, Anand P. Functional MRI brain imaging studies using the Contact Heat Evoked Potential Stimulator (CHEPS) in a human volunteer topical capsaicin pain model. J Pain Res 2011;4:365-71.

214. Shin LM, Dougherty DD, Orr SP, Pitman RK, Lasko M, Macklin ML, Alpert NM, Fischman AJ, Rauch SL. Activation of anterior paralimbic structures during guilt-related script-driven imagery. Biol Psychiatry. $2000 \mathrm{Jul} 1 ; 48(1): 43-50$

215. Singer T, Seymour B, O'Doherty J, Kaube H, Dolan RJ, Frith CD. Empathy for pain involves the affective but not sensory components of pain. Science 2004;303:1157-62.

216. Soria ED, Fine EJ. Disappearance of thalamic pain after parietal subcortical stroke. Pain 1991;44:285-8.

217. Sprenger C, Eippert F, Finsterbusch J, Bingel U, Rose M, Büchel C. Attention modulates spinal cord responses to pain. Curr Biol. 2012; 22:1019-22

218. Steriade $M$, Contreras D, Curró Dossi R, Nuñez A. The slow $(<1 \mathrm{~Hz})$ oscillation in reticular thalamic and thalamocortical neurons: scenario of sleep rhythm generation in interacting thalamic and neocortical networks. J Neurosci. 1993;13:3284-99. 
219. Talbot JD, Marrett S, Evans AC, Meyer E, Bushnell MC, Duncan GH. Multiple representations of pain in human cerebral cortex. Science 1991;251:1355-58.

220. Tanaka S, Osari S, Ozawa M, Yamanouchi H, Goto Y, Matsuda H, Nonaka I. Recurrent pain attacks in a 3-year-old patient with myoclonus epilepsy associated with ragged-red fibers (MERRF): a singlephoton emission computed tomographic (SPECT) and electrophysiological study. Brain Dev. 1997;19:205-8.

221. Tattersall JE, Cervero F, Lumb BM. Viscerosomatic neurons in the lower thoracic spinal cord of the cat: excitations and inhibitions evoked by splanchnic and somatic nerve volleys and by stimulation of brain stem nuclei. J Neurophysiol 1986;56:1411-23

222. Theodore WH, Gaillard WD. Positron emission tomography in neocortical epilepsies. Adv Neurol 2000;84:435-46.

223. Tracey I, Ploghaus A, Gati JS, Clare S, Smith S, Menon RS, Matthews PM. Imaging attentional modulation of pain in the periaqueductal gray in humans. J Neurosci 2002;22:2748-52.

224. Tracey I, Mantyh PW. The cerebral signature for pain perception and its modulation. Neuron. 2007;55:377-91.

225. Tsubokawa T, Katayama Y, Yamamoto T, Hirayama T, Koyama S. Treatment of thalamic pain by chronic motor cortex stimulation. Pacing Clin Electrophysiol 1991a;14:131-4.

226. Tsubokawa T, Katayama Y, Yamhamoto T, Hirayama T, Koyama S. Chronic motor cortex stimulation in patients with chronic pain. J Neurosurg 1993, 78: 393-401

227. Usui C, Hatta K, Doi N, Nakanishi A, Nakamura H, Nishioka K, Arai H. Brain perfusion in fibromyalgia patients and its differences between responders and poor responders to gabapentin. Arthritis Res Ther. 2010;12(2):R64.

228. Valet M, Sprenger T, Boecker H, Willoch F, Rummeny E, Conrad B, Erhard P, Tolle TR. Distraction modulates connectivity of the cingulo-frontal cortex and the midbrain during pain--an fMRI analysis. Pain 2004; 109:399-408.

229. Vogt BA. Pain and emotion interactions in subregions of the cingulate gyrus. Nat Rev Neurosci. 2005;6: 533-544.

230. Vanhaudenhuyse A, Boly M, Balteau E, Schnakers C, Moonen G, Luxen A, Lamy M, Degueldre C, Brichant JF, Maquet $P$, Laureys S, Faymonville ME. Pain and non-pain processing during hypnosis: a thulium-YAG event-related fMRI study. Neuroimage 2009;47:1047-54.

231. Wager TD, Rilling JK, Smith EE, Sokolik A, Casey KL, Davidson RJ, Kosslyn SM, Rose RM, Cohen JD. Placebo-induced changes in FMRI in the anticipation and experience of pain. Science 2004; 303:11627.

232. Wager TD, Atlas LY, Lindquist MA, Roy M, Woo CW, Kross E. An fMRI-based neurologic signature of physical pain. N Engl J Med. 2013;368:1388-97.

233. Wanigakesera V, Lee MC, Rogers R, Hu P, Tracey I. Neural correlates of an injury-free model of central sensitisation induced by opioid withdrawal in humans. J Neurosci 2011; 31:2835-42.

234. Wasan AD, Loggia ML, Chen LQ, Napadow V, Kong J, Gollub RL. Neural correlates of chronic low back pain measured by arterial spin labeling. Anesthesiology 2011;115:364-74.

235. Weinand ME, Carter LP, Patton DD, Oommen KJ, Labiner DM, Talwar D. Long-term surface cortical cerebral blood flow monitoring in temporal lobe epilepsy. Neurosurgery 1994;35:657-64. 
236. Weng HR, Lee JI, Lenz FA, Schwartz A, Vierck C, Rowland L, Dougherty PM. Functional plasticity in primate somatosensory thalamus following chronic lesion of the ventral lateral spinal cord. Neuroscience. 2000;101:393-401.

237. Weng HR, Lenz FA, Vierck C, Dougherty PM. Physiological changes in primate somatosensory thalamus induced by deafferentation are dependent on the spinal funiculi that are sectioned and time following injury. Neuroscience. 2003;116:1149-60.

238. Wicker B, Keysers C, Plailly J, Royet JP, Gallese V, Rizzolatti G. Both of us disgusted in My insula: the common neural basis of seeing and feeling disgust. Neuron 2003; 40:655-64.

239. Wiech K, Seymour B, Kalisch R, Stephan KE, Koltzenburg M, Driver J, Dolan RJ. Modulation of pain processing in hyperalgesia by cognitive demand. Neuroimage 2005;27:59-69.

240. Wiech K, Kalisch R, Weiskopf N, Pleger B, Stephan KE, Dolan RJ. Anterolateral prefrontal cortex mediates the analgesic effect of expected and perceived control over pain. J Neurosci. 2006;26:115019.

241. Wiech K, Ploner M, Tracey I. Neurocognitive aspects of pain perception. Trends Cogn Sci 2008;12:30613.

242. Wiech K, Farias M, Kahane G, Shackel N, Tiede W, Tracey I. An fMRI study measuring analgesia enhanced by religion as a belief system. Pain 2008;139:467-76.

243. Wiech K, Lin CS, Brodersen KH, Bingel U, Ploner M, Tracey I. Anterior insula integrates information about salience into perceptual decisions about pain. J Neurosci. 2010;30:16324-31.

244. Wik G, Fischer H, Bragée B, Kristianson M, Fredrikson M. Retrosplenial cortical activation in the fibromyalgia syndrome. Neuroreport. 2003;14:619-21.

245. Willer, J.C., Boureau, F., Albe-Fessard, D., Supraspinal influences on nociceptive flexion reflex and pain sensation in man. Brain Res. 1979; 179: 61-68

246. Willis WD, AlChaer ED, Quast MJ, Westlund KN. A visceral pain pathway in the dorsal column of the spinal cord. PNAS $1999: 96: 7675-79$.

247. Willoch F, Gamringer U, Medele R, Steude U, Tolle TR; PET activation study. Analgesia by electrostimulation of the trigeminal ganglion in patients with trigeminopathic pain: a PET activation study. Pain 2003;103:119-30

248. Witting N, Kupers RC, Svensson P, Arendt-Nielsen L, Gjedde A, Jensen TS. Experimental brush-evoked allodynia activates posterior parietal cortex. Neurology 2001;57:1817-24.

249. Witting N, Kupers RC, Svensson P, Jensen TS. A PET activation study of brush-evoked allodynia in patients with nerve injury pain. Pain 2006;120:145-54.

250. Wittmann M, van Wassenhove V, Craig AD, Paulus MP. The neural substrates of subjective time dilation. Front Hum Neurosci. 2010;4:2.

251. Woods RP, lacoboni M, Mazziotta JC. Bilateral spreading cerebral hypoperfusion during spontaneous migraine headache. N Engl J Med 1994;331:1689-92

252. Yamashiro K, Iwayama K, Kurihara M, Mori K, Niwa M, Tasker RR, Albe-Fessard D. Neurones with epileptiform discharge in the central nervous system and chronic pain. Experimental and clinical investigations. Acta Neurochir Suppl 1991;52:130-2. 
253. Yamashiro K, Mukawa J, Terada Y, Tomiyama N, Ishida A, Mori K, Tasker RR, Albe-Fessard D. Neurons with high-frequency discharge in the central nervous system in chronic pain. Stereotact Funct Neurosurg. 1994;62:290-4.

254. Yarnitsky D, Barron SA, Bental E. Disappearance of phantom pain after focal brain infarction. Pain 1988;32:285-7.

255. Yunus MB, Young CS, Saeed SA, Mountz JM, Aldag JC. Positron emission tomography in patients with fibromyalgia syndrome and healthy controls. Arthritis Rheum. 2004;51:513-8.

256. Zambreanu L, Wise RG, Brooks JC, lannetti GD, Tracey I. A role for the brainstem in central sensitisation in humans. Evidence from functional magnetic resonance imaging. Pain 2005;114 : $397-$ 407. 


\section{Figure Legends}

Figure 1. Schematic representation of interacting pain matrices. The list of anatomical structures involved reflects the regions activated when a "full pain matrix" is obtained using PET-scan or fMRI, and is of course not exhaustive of all the regions that can participate to the processing of noxious signals. Please note that although the flux of sensory input progresses from left to right, continuous information transfer between matrices creates a dynamic and continuously reconstructing pattern of interactions. Lastly, although not indicated with further arrows, pain memories can also change pain perception by affecting both internal affective states and attentional modulation.

Figure 2. Graphical summary of reported incidence in regional brain activation during experimental and neuropathic allodynia / hyperalgesia. Data from 39 reports published between 1991 and 2012 (see Tables 1 \& 2). The lower panels summarise the most significant differences between experimental and neuropathic allodynia. Arrows indicate significant differences in reported frequency. Activation of the ipsilateral opercular and insular cortices, relative to their contralateral counterparts, was more frequently reported during neuropathic than experimental allodynia (lower right panel). On the contrary, activation of perigenual, orbitofrontal and lateral prefrontal cortices was significantly more prevalent during experimental allodynia (lower right).

Figure 3. Enhanced activation of ipsilateral operculo-insular areas during neuropathic allodynia, peripheral (top) or central (bottom). In each case the upper row depicts regions activated during innocuous brush to the healthy side (control), and the lower row the effect of brushing identically the allodynic side, where stimuli become painful. Control stimuli mainly activate the contralateral operculum and insula, while allodynic stimuli activate predominantly the ipsilateral regions. Reproduced from Witting et al Pain 2006, and Peyron et al Neurology 2004. See text for details.

Figure 4. Neuropathic allodynia is often characterised by a lack of response in perigenual and orbitofrontal regions, and these regions are commonly activated by interventions improving pain. The figure depicts the stereotaxic projection of cingulate activation peaks during different interventions resulting in pain relief in healthy subjects and pain patients: 1 - healthy subjects during experimental pain. Pl: placebo effect: 1: (Casey et al 2000); 2: (Wager et al 2004); 3: (Petrovic et al 2002); 4: (Bingel et al 2004). •. O: opioid effect: 1: (Adler et al., 1997); 2: (Firestone et al., 1996); 3: (Petrovic et al., 2002). •. Green letters : physiological modulations of pain: D: distraction: D: (Bantick et al., 2002); Dv: (Valet et al., 2004); C: controllability: (Salomons et al., 2004). -2- patients during clinical pain, A: anesthetic blocks: (Hsieh et al., 1995); Th: thalamic stimulation: (Kupers et al., 2000); Th: (Davis et al., 2000). •.M: motor cortex stimulation 1: (Garcia-Larrea et al., 1999); 2: (Saitoh et al., 2004); 3: (Peyron et al 2007a). •. V: trigeminal stimulation: (Willoch et al 2003). Reproduced from Peyron et al Neuroimage 2007, with permission. 